\title{
Penerapan Kombinasi Metode Entropy dan Extended Promethee II Dalam Menentukan Kepala Jurusan Pada SMK
}

\author{
Ahmad Zulfandi \\ Fakultas Ilmu Komputer dan Teknologi Informasi, Prodi Teknik Informatika, Universitas Budi Darma, Medan, Indonesia \\ Email: azfandi99@gmail.com \\ Submitted: 26/07/2021; Accepted: 15/11/2021; Published: 30/11/2021
}

\begin{abstract}
Abstrak-Penyelenggaraan pendidikan di Sekolah Menengah Kejuruan (SMK) tidak lepas dari peran penting seorang Kepala Jurusan, terutama dalam matapelajaran kejuruan yang menjadi bidang keahliannya. Kepala jurusan memiliki banyak tugastugas penting yang berhubungan dengan bidang keahliaannya. Penentuan kepala jurusan pada SMK Negeri 1 Perbaungan dilakukan setiap tahunnya, yang dimana para kandidat dinilai secara keseluruhan oleh kepala sekolah dan kemudian ditentukan seorang kepala jurusan yang pantas untuk menjadi kepala jurusan pada periode tersebut. Untuk mendapatkan hasil yang lebih baik dalam menentukan kepala jurusan dapat menggunakan Sistem Pendukung Keputusan (SPK) sebagai aplikasi yang membantu kepala sekolah dalam menentukan kepala jurusan. Metode yang cocok digunakan berdasarkan kasus ini adalah kombinasi metode Entropy dan Extended Promethee II yang dimana metode ini dapat membanding antara satu alternatif dengan alternatif lainnya berdasarkan setiap nilai kriteria masing-masing. Pembobotannya pun juga menggunakan metode entropy sehingga nilai bobot yang dihasilkan dari nilai setiap alternatif dapat lebih akurat. Perangkingan yang dihasilkan metode EXPROM II menampilkan kandidat yang terbaik untuk menjadi kepala jurusan.
\end{abstract}

Kata Kunci: Kepala Jurusan; Sistem Pendukung Keputusan; Entropy; EXPROM II

\begin{abstract}
The implementation of education in Vocational High School can not be separated from the important role of a Head of Department, especially in vocational education that becomes his area of expertise. The head of the department has many important tasks related to his field of youth. The determination of the head of the department at SMK Negeri 1 Perbaungan is carried out annually, in which the candidates are assessed in their entirety by the principal and then determined a head of the department who is fit to be the head of the department in that period. To get better results in determining the head of the department can use the Decision Support System as an application that helps the principal in determining the head of the department. A suitable method used based on this case is a combination of Entropy and Extended Promethee II methods in which it can compare between one alternative and another based on each criteria value. Weighting also uses entropy method so that the weight value generated from each alternative value can be more accurate. The resulting exprom II method presents the best candidates to be the head of the department.
\end{abstract}

Keywords: Head of the Department; Decision Support System; Entropy; EXPROM II

\section{PENDAHULUAN}

Sekolah Menengah Kejuruan (SMK) merupakan lembaga pendidikan yang berperan menciptakan sumber daya manusia yang berkualitas dan kompeten dibidangnya. Sumber daya manusia yang berkualitas ialah tenaga kerja siap pakai, yakni tenaga kerja yang menunjukkan penguasaan ilmu pengetahuan, teknologi, dan keterampilan yang tinggi diikuti dengan moral, etika, dan karakter diri yang baik. Pembentukan sumber daya manusia yang seperti ini, tidak terlepas dari peran para guru di sekolah yang mengajarkan berbagai keterampilan untuk menunjang siswa-siswinya agar menjadi tenaga kerja siap pakai, kepala jurusan juga memiliki peran penting untuk membentuk generasi muda yang berkualitas dengan membuat program kejuruan yang sesuai dengan kebutuhan dunia kerja. Program kejuruan disusun oleh kepala jurusan masing-masing, yang kemudian diterapkan prosesnya dalam kegiatan belajar mengajar oleh guru kejuruan dan kepala jurusan juga bertugas untuk menentukan jadwal praktek para siswa yang seluruh kegiatannya diawasi oleh kepala jurusan sesuai bidang keahlian.

Pada Sekolah Menengah Kejuruan (SMK) Negeri 1 Perbaungan memiliki beberapa kepala jurusan yang setiap kepala jurusannya bertanggungjawab atas kompetensi keahliannya masing-masing. Penentuan kepala jurusan umumnya dilakukan dengan cara pengangkatan jabatan dari guru kejuruan menjadi kepala jurusan yang sebelumnya diseleksi berdasarkan beberapa kriteria yang sudah ditentukan oleh pihak SMK dan hasil pemilihannya disetujui oleh kepala sekolah. Masalah pada kasus ini adalah proses penentuan kepala jurusan yang digunakan pada SMK Negeri 1 Perbaungan masih kurang akurat, dikarenakan penentuan kepala jurusan masih berupa hasil kesepakatan bersama, tidak dilakukan proses perhitungan data dari beberapa kriteria yang hasilnya diurutkan menggunakan metode tertentu. Hasil yang didapatkan pun belum tentu adalah hasil yang terbaik dari seluruh calon-calon kepala jurusan yang ada.

Proses tersebut dapat dilakukan dengan lebih mudah jika menggunakan Sistem Pendukung Keputusan (SPK), Sistem pendukung keputusan adalah suatu sistem penentu keputusan yang berbasis komputer dan berguna untuk mempermudah dalam menentukan suatu keputusan serta merekomendasikan pilihan terbaik kepada kepala sekolah[1]. Hasil dari SPK tidaklah mutlak harus diikutin oleh kepala sekolah, karena SPK hanya membantu kepala sekolah dalam menentukan keputusannya. Keputusan yang sebenarnya ditentukan oleh kepala sekolah akan tetapi rekomendasi yang diberikan melalui proses SPK dapat dipercaya ketepatannya. Sistem pendukung keputusan memiliki banyak metode yang dapat digunakan dalam pengerjaannya seperti metode AHP, ORESTE, 
PROMETHEE, ELECTRE, TOPSIS, ARAS, PSI dan sebagainya [2], [3]. Tetapi dalam penggunaannya, setiap metode yang digunakan harus sesuai dengan kasus yang ditanganin.

Pada kasus ini, dikarenakan tidak ditentukannya nilai bobot dari pihak instansi, maka penulis menggunakan metode Entropy sebagai metode untuk menentukan nilai bobot dari data-data kriteria yang tersedia. Nilai bobot yang dihasilkan dari metode Entropy bersifat tidak tetap, hasil akan berubah jika salah satu data kriteria berubah. Akumulasi dari bobot setiap kriteria pasti bernilai 1, jika tidak maka perhitungan menggunakan metode Entropy masih salah. Pemeringkatan dalam menentukan kepala jurusan menggunakan metode Extended Promethee II (EXPROM II) yang dalam prosesnya metode ini membandingkan antara satu alternatif dengan alternatif lainnya, sehingga mendapatkan pilihan yang terbaik untuk dijadikan kepala jurusan. Tetapi pada kasus ini tidak bisa hanya menggunakan metode EXPROM II dalam pemrosesannya, karena metode EXPROM II tidak dapat menghasilkan bobotnya sendiri untuk melakkan pemeringkatan. Oleh karena itu, penulis mengkombinasikan metode Entropy dan EXPROM II untuk saling melengkapi dalam pemrosesan untuk menentukan kepala jurusan pada SMK Negeri 1 Perbaungan.

\section{METODOLOGI PENELITIAN}

\subsection{Sistem Pendukung Keputusan}

Konsep sistem pendukung keputusan pertama kali diungkap pada tahun 1971 oleh Michael Scoot Morton dengan istilah Management Decision System. Kemudian beberapa lembaga, perusahaan dan perguruan tinggi mulai melakukan penelitian dan membangun sistem pendukung keputusan, sehingga dapat disimpulkan bahwa sistem ini merupakan suatu sistem berbasis komputer yang menghasilkan berbagai alternatif keputusan dan ditujukkan untuk membantu pengambilan keputusan dalam memanfaatkan data dan model tertentu untuk memecahkan berbagai persoalan yang terstruktur maupun yang tidak terstruktur. Sistem Pendukung Keputusan (SPK) atau yang disebut Decision Support System (DSS) adalah sistem yang dapat dikembangkan, berorientasi kepada perencanaan masa yang akan mendatang serta tidak direncanakan interval atau priode waktu dalam pemakaiannya[4]-[6].

\subsection{Metode Entropy}

Entropy dapat digunakan untuk menentukan bobot dengan menghasilkan kriteria dengan variasi nilai yang tertinggi dan bobot yang tinggi. Bobot adalah tingkatan kepentingan relatif dari kriteria yang digunakan dalam suatu penilaian.bobot kriteria dalam suatu penilaian ditentukan melalui opini pengambil keputusan. Apabila terdapat beberapa pengambilan keputusan, maka proses pembobotan kriteria menjadi lebih sulit karena setiap pengambilan keputusan mempunyai preferensi yang berbeda. Metode pembobotan yang bisa mengakomodasi hal ini, salah satunya adalah metode metode pembobotan entropy. Selain itu metode ini juga tidak mensyaratkan bahwa satuan maupun range dari tiap kriteria harus sama. Hal ini dimungkinkan karena sebelum diolah, semua data akan dinormalisasi dulu sehingga akan bernilai antara 0-1[7], [8]. Berikut langkah-langkah perhitungan pembobotan entropy, yaitu :

1. Menentukan data awal

Setiap pengambil keputusan memberikan nilai sesuai preferensinya yang menunjukan kepentingan suatu kriteria tertentu.

2. Normalisasi data awal

Normalisasikan tiap nilai kriteria dengan bilangan fuzzy yang sudah ditentukan, hasil normalisasi tersebut dinyatakan $k_{i j}$.

3. Menentukan nilai matriks $\left(a_{\mathrm{ij}}\right)$

$\mathrm{a}_{\mathrm{ij}}=\frac{K_{i j}}{\sum_{i=1}^{m} \sum_{j=1}^{n} K_{i j}}$

dimana : $\quad \mathrm{a}_{\mathrm{ij}}=$ hasil perhitungan matriks data kriteria.

$\mathrm{k}_{\mathrm{ij}}=$ nilai setiap kriteria dari normalisasi data awal

$i=$ responden ke $1,2, \ldots . \mathrm{i}$

$j=$ kriteria ke $1,2, \ldots . j$

$m=$ jumlah pengam bil keputusan

$n=$ jumlah kriteria

4. Perhitungan nilai entropy untuk setiap kriteria.

$E_{j}=\left[\frac{-1}{\ln m} \sum_{i=1}^{m}\left[a_{i j} \ln \left(a_{i j}\right)\right]\right]$

Dimana : $\quad E_{j}=$ nilai bobot entropy.

$\ln =$ nilai log dari total pengambilan keputusan.

5. Perhitungan dispersi untuk setiap kriteria.

$D_{j}=1-E_{j}$

Dimana $: D_{j}=$ nilai dispersi entropy.

6. Normalisasi nilai dispersi. 


$$
W_{j}=\frac{D_{j}}{\sum D_{j}}
$$

Dimana $: W_{j}=$ nilai normalisasi dispersi (bobot prioritas kriteria)

\subsection{Metode The Extended Promethee II}

The Extended Promethee II atau dapat juga disebut dengan exprom II adalah perbandingan deviasi atau dapat diartikan sebagai jarak antar alternatif yang berpasangan untuk setiap kriteria. Untuk metode ini, nilai relatif dari salah satu alternatif yang lain dapat didefinisikan oleh dua indeks preferensi[9], [10]. Algoritma dalam penyelesaian Sistem Pendukung Keputusan (SPK) dengan metode EXPROM II. Adapun antara lain [11], sebagai berikut :

1. Membuat Matriks Keputusan.

Matriks keputusan yaitu matriks yang terdiri dari nilai alternatif $i$ untuk setiap kriteria $j$.

2. Normalisai Matriks Keputusan

Untuk kriteria benefit:

$r_{i j} \frac{\left[X_{i j}-\min \left(X_{i j}\right)\right]}{\left[\max \left(X_{i j}\right)-\min \left(X_{i j}\right)\right]}(\mathrm{i}=1,2, \ldots, \mathrm{m} ; \mathrm{j}=1,2, . . \mathrm{n})$

Untuk kriteria cost

$r_{i j} \frac{\left[\max \left(X_{i j}\right)-X_{i j}\right]}{\left[\max \left(X_{i j}\right)-\min \left(X_{i j}\right)\right]}$

dimana: $r i j=$ matriks ternormalisasi

$$
\begin{aligned}
& i=\text { alternatif } \\
& j=\text { kriteria }
\end{aligned}
$$

3. Penentuan Fungsi Preferensi $P_{j}\left(i, i^{\prime}\right)$.

Persamaan Fungsi Preferensi $P_{j}\left(i, i^{\prime}\right)$ diberikan dibawah ini

$P_{i j}\left(i, i^{\prime}\right)=0$ if $r_{i j} \leq r_{i, j}$

$P_{i j}\left(i, i^{\prime}\right)=\left(r_{i j}-r_{i \prime j}\right)$ if $r_{i j}>r_{i \prime}$

Dimana: $P_{i j}=$ Fungsi Preferensi

$$
\begin{aligned}
i & =\text { alternatif } \\
i^{\prime} & =\text { alternatif yang akan dipasangkan }
\end{aligned}
$$

4. Menghitung Nilai Weak Preference (WP), Menghitung Indeks Prefrensi yang lemah dan mempertimbangkan kriteria dengan bobot yang berbeda untuk setiap kriteria persamaannya sebagai berikut:

$\mathrm{WP}\left(i, i^{\prime}\right)=\left[\sum_{j=1}^{n} W_{j} \times P_{j}(i, i)\right] \sum_{j=1}^{n} W_{j}$

Dimana: $\mathrm{WP}=$ Weak Preference

$$
\begin{aligned}
\mathrm{n} & =\text { jumlah kriteria } \\
W_{j} & =\text { bobot kriteria } j
\end{aligned}
$$

5. Menghitung Nilai $S P_{j}\left(i, i^{\prime}\right)$

Menentukan nilai fungsi preferensi yang kuat $S P_{j}\left(i, i^{\prime}\right)$ sebagai berikut:

$S P_{j}\left(i, i^{\prime}\right)=\left[\max \left(0, d_{j}-L_{j}\right] /\left[d m_{j}-L_{j}\right]\right.$

dimana: $\mathrm{SP} j=$ Strict Preference kriteria $j$

$$
\begin{aligned}
\mathrm{dj} & =\text { rij-ri'j } \\
d m_{j} & =1 \\
L_{j} & =0
\end{aligned}
$$

6. Menghitung Nilai Strict Preference (SP)

$S P_{j}\left(i, i^{\prime}\right)=\left[\sum_{j=1}^{n} W_{j} \mathrm{xS} P_{j}(i, i)\right] \sum_{j=1}^{n} W_{j}$

Dimana: $\mathrm{SP}=$ Weak Preference

$$
\mathrm{n}=\text { jumlah kriteria }
$$

$W_{j}=$ bobot kriteria $j$

7. Menghitung Nilai Total Preference atau TP $\left(i, i^{\prime}\right)$

$\mathrm{TP}\left(i, i^{\prime}\right)=\operatorname{Min}\left[1, \mathrm{WP}\left(i, i^{\prime}\right)+\mathrm{SP}\left(i, i^{\prime}\right)\right]$

8. Menghitung aliran yang keluar (Entering) dan aliran yang masuk (Leaving Flow) menggunakann persamaan:

Untuk arah keluar (positif) pada alternatif $i$ :

$\varphi^{+}(\mathrm{i})=\frac{1}{m-1} \sum_{j=1}^{n} \operatorname{TP}\left(i, i^{\prime}\right)\left(i \neq i^{\prime}\right)$

Untuk arah masuk (negatif) pada alternatif $i$ :

$\varphi^{-}(\mathrm{i})=\frac{1}{m-1} \sum_{j=1}^{n} \operatorname{TP}\left(i, i^{\prime}\right)\left(i \neq i^{\prime}\right)$

dimana: $i=$ alternatif

$i^{\prime}=$ alternatif yang dipasangkan 


$$
\begin{aligned}
\mathrm{m} & =\text { jumlah alternatif } \\
\mathrm{n} & =\text { jumlah kriteria }
\end{aligned}
$$

aliran keluar berarti berapa banyak alternatif yang mendominasikan alternatif

lainnya, sedangkan aliran keluar yaitu berapa banyak alternatif didomikasikan oleh alternatif yang lainnya.

9. Menghitung Net Flow

Dari perhitungan perangkingan $\varphi($ i) untuk alternatif lain:

$\varphi(\mathrm{i})=\varphi^{+}(\mathrm{i})-\varphi^{-}(\mathrm{i})$

Yang terakhir adalah penentuan rangking, metode EXPROM II ini merupakan pengambilan dari Nilai yang terbaik atau alternatif terbaik adalah alternatif yang memiliki nilai $\varphi(\mathrm{i})$ tertinggi.

\section{HASIL DAN PEMBAHASAN}

Pada bab ini penulis menjelaskan bagaimana proses dari pengambilan data-data yang diperlukan sampai dengan tahap perancangan penelitian ini. Metode pengumpulan data dilakukan dengan cara wawancara langsung ke bagian yang berhubungan di instansi tempat penelitian. Penulis terlebih dahulu menemui wakil kepala sekolah dan kepala sekolah untuk mendapatkan izin penelitian pada SMK Negeri 1 Perbaungan kemudian menemui bagian tata usaha untuk mendapatkan surat balasan izin penelitian dan untuk mendapatkan data-data yang diperlukan untuk penelitian. Data-data umum yang diperoleh penulis dari bagian tata usaha berupa sejarah instansi, logo dan makna logo, struktur organisasi dan lain sebagainya. Penulis mendapatkan data dengan cara meminta duplikat file dan melakukan wawancara langsung dengan kepala tata usaha. Sedangkan data-data untuk proses perancangan seperti kriteria penentuan kepala jurusan dan prosedurnya penulis mendapatkannya dengan cara melakukan wawancara langsung dengan kepala sekolah SMK Negeri 1 Perbaungan.

Setelah terkumpulnya data-data yang diperlukan untuk penelitian, tahap selanjutnya penulis melakukan tahap studi kepustakaan untuk mendukung perancangan sistem yang akan penulis rancang. Penulis mengambil sumber-sumber referensi dari jurnal, buku, dan $e$-book untuk dijadikan referensi dalam membut perancangan sistem yang sesuai dengan penelitian ini.

\subsection{Penerapan Metode Entropy dan Exprom II}

Berikut ini kriteria-kriteria yang sudah ditentukan dan disetujui oleh kepala sekolah dan kepala tata usaha ketika penulis melakukan riset selama beberapa hari di SMK Negeri 1 Perbaungan. Kriteria-kriterianya adalah pendidikan terakhir, bidang keahlian, lama masa kerja, memiliki NUPTK, dan kedisiplinan. Berikut adalah tabel kriteriakriteria yang penulis gunakan dalam proses perhitungan menggunakan metode entropy dan exprom II:

Tabel 1. Kriteria

\begin{tabular}{cc}
\hline Kode & Nama \\
\hline C1 & Pendidikan (P) \\
C2 & Bidang Keahlian (BK) \\
C3 & Masa Kerja (MK) \\
C4 & NUPTK (N) \\
C5 & Kedisiplin (K) \\
\hline
\end{tabular}

Data alternatif di atas dibuat menjadi nilai-nilai sesuai dengan kriteria dan penilaian yang telah dijelaskan pada tabel-tabel sebelumnya sesuai dengan nilai fuzzy yang telah ditentukan.

Tabel 2. Rating kecocokan Alternatif dan Kriteria

\begin{tabular}{cccccc}
\hline & $\mathrm{C}_{1}$ & $\mathrm{C}_{2}$ & $\mathrm{C}_{3}$ & $\mathrm{C}_{4}$ & $\mathrm{C}_{5}$ \\
\hline $\mathrm{A} 1$ & 4 & 1 & 35 & 1 & 4 \\
$\mathrm{~A} 2$ & 5 & 0 & 11 & 1 & 5 \\
$\mathrm{~A} 3$ & 4 & 1 & 10 & 1 & 4 \\
$\mathrm{~A} 4$ & 4 & 0 & 8 & 0 & 4 \\
$\mathrm{~A} 5$ & 4 & 1 & 11 & 1 & 4 \\
$\mathrm{~A} 6$ & 5 & 0 & 14 & 1 & 4 \\
$\mathrm{~A} 7$ & 4 & 0 & 8 & 1 & 4 \\
$\mathrm{~A} 8$ & 4 & 1 & 11 & 1 & 5 \\
\hline
\end{tabular}

Metode pembobotan Entropy merupakan metode pengambilan keputusan yang memberikan sekelompok kriteria dan menaksir preferensi suatu bobot. Berikut adalah langkah-langkah dari metode entropy:

1. Penentuan data awal matriks 


$$
X_{i j}=\left[\begin{array}{ccccc}
4 & 1 & 35 & 1 & 4 \\
5 & 0 & 11 & 1 & 5 \\
4 & 1 & 10 & 1 & 4 \\
4 & 0 & 8 & 0 & 4 \\
4 & 1 & 11 & 1 & 4 \\
5 & 0 & 14 & 1 & 4 \\
4 & 0 & 8 & 1 & 4 \\
4 & 1 & 11 & 1 & 5
\end{array}\right]
$$

Dimana : C1, C2, C3, C4, dan C5 adalah Benefit

$$
\operatorname{Max}\left(X_{i j}\right): \mathrm{C} 1=5, \mathrm{C} 2=1, \mathrm{C} 3=35, \mathrm{C} 4=1, \mathrm{C} 5=5
$$

2. Penormalisasian matriks keputusan $\left(K_{i j}\right)$

Normalisasi matriks diperoleh apabila kriteria benefit maka nilai matriks dibagi dengan nilai maksimum dan apabila kriteria cost maka nilai minimum kriteria dibagi dengan nilai matriks. Pada langkah ini menggunakan persamaan 1

$$
\begin{aligned}
& \mathrm{C} 1=\text { Pendidikan } \\
& K_{11}=\frac{4}{5}=0,8 \\
& K_{21}=\frac{5}{5}=1 \\
& K_{31}=\frac{4}{5}=0,8 \\
& K_{41}=\frac{4}{5}=0,8 \\
& K_{51}=\frac{4}{5}=0,8 \\
& K_{61}=\frac{5}{5}=1 \\
& K_{71}=\frac{4}{5}=0,8 \\
& K_{81}=\frac{4}{5}=0,8 \\
& \mathrm{C} 2=\text { Bidang Keahlian } \\
& K_{12}=\frac{1}{1}=1 \\
& K_{22}=\frac{0}{1}=0 \\
& K_{32}=\frac{1}{1}=1 \\
& K_{42}=\frac{0}{1}=0 \\
& K_{52}=\frac{1}{1}=1 \\
& K_{62}=\frac{0}{1}=0 \\
& K_{72}=\frac{0}{1}=0 \\
& K_{82}=\frac{1}{1}=1 \\
& \mathrm{C} 3=\text { Masa Kerja } \\
& K_{13}=\frac{35}{35}=1 \\
& K_{23}=\frac{11}{35}=0,3143 \\
& K_{33}=\frac{10}{35}=0,2857 \\
& K_{43}=\frac{8}{35}=0,2286
\end{aligned}
$$

$$
\begin{aligned}
& K_{53}=\frac{11}{35}=0,3143 \\
& K_{63}=\frac{14}{35}=0,4 \\
& K_{73}=\frac{8}{35}=0,2286 \\
& K_{83}=\frac{11}{35}=0,3143 \\
& \mathrm{C} 4=\text { NUPTK } \\
& K_{14}=\frac{1}{1}=1 \\
& K_{24}=\frac{1}{1}=1 \\
& K_{34}=\frac{1}{1}=1 \\
& K_{44}=\frac{0}{1}=0 \\
& K_{54}=\frac{1}{1}=1 \\
& K_{64}=\frac{1}{1}=1 \\
& K_{74}=\frac{1}{1}=1 \\
& K_{84}=\frac{1}{1}=1 \\
& \mathrm{C}_{5}=\text { Kedisiplinan } \\
& K_{15}=\frac{4}{5}=0,8 \\
& K_{25}=\frac{5}{5}=1 \\
& K_{35}=\frac{4}{5}=0,8 \\
& K_{45}=\frac{4}{5}=0,8 \\
& K_{55}=\frac{5}{5}=0,8 \\
& K_{65}=\frac{4}{5}=0,8 \\
& K_{75}=\frac{4}{5}=0,8 \\
& K_{85}=\frac{5}{5}=1
\end{aligned}
$$

Tabel 3. Hasil penormalisasian matriks

\begin{tabular}{cccccc}
\hline \multirow{2}{*}{ Alternatif } & \multicolumn{5}{c}{ Kriteria } \\
\cline { 2 - 6 } & P (B) & BK (B) & MK (B) & N (B) & K(B) \\
\hline A1 & 0,8 & 1 & 1 & 1 & 0,8 \\
A2 & 1 & 0 & 0,3143 & 1 & 1 \\
A3 & 0,8 & 1 & 0,2857 & 1 & 0,8 \\
A4 & 0,8 & 0 & 0,2286 & 0 & 0,8 \\
A5 & 0,8 & 1 & 0,3143 & 1 & 0,8 \\
A6 & 1 & 0 & 0,4 & 1 & 0,8 \\
A7 & 0,8 & 0 & 0,2286 & 1 & 0,8 \\
A8 & 0,8 & 1 & 0,3143 & 1 & 1 \\
Sum Kij & 6,8 & 4 & 3,0858 & 7 & 6,8 \\
\hline
\end{tabular}

3. Menentukan nilai matriks $a_{i j}$ 
Pada langkah ini menggunakan persamaan 2
$\mathrm{C} 1=$ Pendidikan
$a_{11}=\frac{0,8}{6,8}=0,1176$
$a_{21}=\frac{1}{6,8}=0,1471$
$a_{31}=\frac{0,8}{6,8}=0,1176$
$a_{41}=\frac{0,8}{6,8}=0,1176$
$a_{51}=\frac{0,8}{6,8}=0,1176$
$a_{61}=\frac{1}{6,8}=0,1471$
$a_{71}=\frac{0,8}{6,8}=0,1176$
$a_{81}=\frac{0,8}{6,8}=0,1176$
$\mathrm{C} 2=$ Bidang Keahlian
$a_{12}=\frac{1}{4}=0,25$
$a_{22}=\frac{0}{4}=0$
$a_{32}=\frac{1}{4}=0,25$
$a_{42}=\frac{0}{4}=0$
$a_{52}=\frac{1}{4}=0,25$
$a_{62}=\frac{0}{4}=0$
$a_{72}=\frac{0}{4}=0$
$a_{82}=\frac{1}{4}=0,25$
$a_{53}=\frac{0,3143}{3,0857}=0,1019$
$a_{63}=\frac{0,4}{3,0857}=0,1296$
$a_{73}=\frac{0,2286}{3,0857}=0,0741$
$a_{83}=\frac{0,3143}{3,0857}=0,1019$
$\mathrm{C} 4=$ NUPTK
$a_{14}=\frac{1}{7}=0,1429$
$a_{24}=\frac{1}{7}=0,1429$
$a_{34}=\frac{1}{7}=0,1429$
$a_{44}=\frac{0}{7}=0$
$a_{54}=\frac{1}{7}=0,1429$
$a_{64}=\frac{1}{7}=0,1429$
$a_{74}=\frac{1}{7}=0,1429$
$a_{84}=\frac{1}{7}=0,1429$
C5 = Kedisiplinan
$a_{15}=\frac{0,8}{6,8}=0,1176$
$a_{25}=\frac{1}{6,8}=0,1471$
$a_{35}=\frac{0,8}{6,8}=0,1176$
$a_{45}=\frac{0,8}{6,8}=0,1176$
$a_{55}=\frac{0,8}{6,8}=0,1176$
$a_{13}=\frac{1}{3,0857}=0,3241$
$a_{65}=\frac{0,8}{6,8}=0,1176$
$a_{23}=\frac{0,3143}{3,0857}=0,1019$
$a_{33}=\frac{0,2857}{3,0857}=0,0926$
$a_{43}=\frac{0,2286}{3,0857}=0,0741$
$a_{75}=\frac{0,8}{6,8}=0,1176$
$a_{85}=\frac{1}{6,8}=0,1471$

Tabel 4. Hasil nilai matriks aij

\begin{tabular}{cccccc}
\hline \multirow{2}{*}{ Alternatif } & \multicolumn{5}{c}{ Kriteria } \\
\cline { 2 - 6 } & $\mathrm{P}(\mathrm{B})$ & $\mathrm{BK}(\mathrm{B})$ & $\mathrm{MK}(\mathrm{B})$ & $\mathrm{N}(\mathrm{B})$ & $\mathrm{K}(\mathrm{B})$ \\
\hline A1 & 0,1176 & 0,25 & 0,3241 & 0,1429 & 0,1176 \\
A2 & 0,1471 & 0 & 0,1019 & 0,1429 & 0,1471 \\
A3 & 0,1176 & 0,25 & 0,0926 & 0,1429 & 0,1176 \\
A4 & 0,1176 & 0 & 0,0741 & 0 & 0,1176 \\
A5 & 0,1176 & 0,25 & 0,1091 & 0,1429 & 0,1176 \\
A6 & 0,1471 & 0 & 0,1296 & 0,1429 & 0,1176 \\
A7 & 0,1176 & 0 & 0,0741 & 0,1429 & 0,1176 \\
A8 & 0,1176 & 0,25 & 0,1091 & 0,1429 & 0,1471 \\
\hline
\end{tabular}

4. Perhitungan nilai entropy untuk setiap kriteria $\left(E_{j}\right)$

Pada langkah ini menggunakan persamaan

$\mathrm{C} 1=$ Pendidikan

$$
\begin{aligned}
a_{11} & =\left[a_{11} \ln a_{11}\right] \\
& =[0,1176(\ln 0,1176)] \\
& =-0,2518 \\
a_{21} & =[0,1471(\ln 0,1471)] \\
a_{31} & =-0,2819 \\
a_{41} & =[0,1176(\ln 0,1176)] \\
& =-0,2518 \\
a_{51} & =[0,1176(\ln 0,1176)] \\
& =-0,2518
\end{aligned}
$$




$$
\begin{aligned}
& \begin{aligned}
& =-0,2518 \\
a_{61} & =[0,1471(\ln 0,1471)]
\end{aligned} \\
& =-0,2819 \\
& a_{71}=[0,1176(\ln 0,1176)] \\
& =-0,2518 \\
& a_{81}=[0,1176(\ln 0,1176)] \\
& =-0,2518 \\
& \sum_{i=1}^{m}\left[a_{i j} \ln \left(a_{i j}\right)\right]=-2,0744 \\
& E_{1} \quad=\frac{-1}{\ln (8)}-2,0744 \\
& =\frac{-1}{2,0794}-2,0744 \\
& E_{1} \quad=0,9976 \\
& \mathrm{C} 2=\text { Bidang Keahlian } \\
& a_{12}=[0,25(\ln 0,25)] \\
& =-0,3466 \\
& a_{22}=[0(\ln 0)] \\
& =0 \\
& a_{32}=[0(\ln 0)] \\
& =0 \\
& a_{42}=[0(\ln 0)] \\
& =0 \\
& a_{52}=[0,25(\ln 0,25)] \\
& =-0,3466 \\
& a_{62}=[0(\ln 0)] \\
& =0 \\
& a_{72}=[0(\ln 0)] \\
& =0 \\
& a_{82}=[0,25(\ln 0,25)] \\
& =-0,3466 \\
& \sum_{i=1}^{m}\left[a_{i j} \ln \left(a_{i j}\right)\right]=-1,3863 \\
& E_{2} \quad=\frac{-1}{\ln (8)}-1,3863 \\
& =\frac{-1}{2,0794}-1,3863 \\
& E_{2} \quad=0,6667 \\
& \text { C3 = Masa Kerja } \\
& a_{13}=[0,3241(\ln 0,3241)] \\
& =-0,3652 \\
& a_{23}=[0,1019(\ln 0,1019)] \\
& =-0,2327 \\
& a_{33}=[0,0926(\ln 0,0926] \\
& =-0,2203 \\
& a_{43}=[0,0741(\ln 0,0741] \\
& =-0,1928 \\
& a_{53}=[0,1019(\ln 0,1019)] \\
& =-0,2327 \\
& a_{63}=[0,1296(\ln 0,1296)] \\
& =-0,2648 \\
& a_{73}=[0,0741(\ln 0,0741] \\
& =-0,1928 \\
& a_{83}=[0,1019(\ln 0,1019)] \\
& =-0,2327 \\
& \sum_{i=1}^{m}\left[a_{i j} \ln \left(a_{i j}\right)\right]=-1,9339 \\
& E_{3} \quad=\frac{-1}{\ln (8)}-1,9339 \\
& =\frac{-1}{2,0794}-1,9339 \\
& E_{3} \quad=0,93 \\
& \mathrm{C} 4=\text { NUPTK } \\
& a_{14}=[0,1429(\ln 0,1429)]
\end{aligned}
$$




$$
\begin{aligned}
& \begin{aligned}
& =-0,2780 \\
a_{24} & =[0,1429(\ln 0,1429)]
\end{aligned} \\
& =-0,2780 \\
& a_{34}=[0,1429(\ln 0,1429)] \\
& =-0,2780 \\
& a_{44}=[0(\ln 0)] \\
& =0 \\
& a_{54}=[0,1429(\ln 0,1429)] \\
& =-0,2780 \\
& a_{64}=[0,1429(\ln 0,1429)] \\
& =-0,2780 \\
& a_{74}=[0,1429(\ln 0,1429)] \\
& =-0,2780 \\
& a_{84}=[0,1429(\ln 0,1429)] \\
& =-0,2780 \\
& \sum_{i=1}^{m}\left[a_{i j} \ln \left(a_{i j}\right)\right]=-1,9459 \\
& E_{4} \quad=\frac{-1}{\ln (8)}-1,9459 \\
& =\frac{-1}{2,0794}-1,9459 \\
& E_{4}=0,9358 \\
& \text { C5 = Kedisiplinan } \\
& a_{15}=[0,1176(\ln 0,1176)] \\
& =-0,2518 \\
& a_{25}=[0,1471(\ln 0,1471)] \\
& =-0,2819 \\
& a_{35}=[0,1176(\ln 0,1176)] \\
& =-0,2518 \\
& a_{45}=[0,1176(\ln 0,1176)] \\
& =-0,2518 \\
& a_{55}=[0,1176(\ln 0,1176)] \\
& =-0,2518 \\
& a_{65}=[0,1176(\ln 0,1176)] \\
& =-0,2518 \\
& a_{75}=[0,1176(\ln 0,1176)] \\
& =-0,2518 \\
& a_{85}=[0,1471(\ln 0,1471)] \\
& =-0,2819 \\
& \sum_{i=1}^{m}\left[a_{i j} \ln \left(a_{i j}\right)\right]=-2,0744 \\
& E_{5} \quad=\frac{-1}{\ln (8)}-2,0744 \\
& =\frac{-1}{2,0794}-2,0744 \\
& E_{5} \quad=0,9976
\end{aligned}
$$

5. Perhitungan dispresi untuk setiap kriteria $D_{j}$

Pada langkah ini menggunakan persamaan 3.4

$$
\begin{aligned}
D_{1} & =1-0,9976 \\
& =0,0024 \\
D_{2} & =1-0,6667 \\
& =0,3333 \\
D_{3} & =1-0,93 \\
& =0,07 \\
D_{4} & =1-0,9358 \\
& =0,0642 \\
D_{5} & =1-0,9976 \\
& =0,0024 \\
\sum D_{j} & =0,4724
\end{aligned}
$$

6. Normalisasi nilai dispersi $W_{j}$

Pada langkah ini menggunakan persamaan 3.5 


$$
\begin{aligned}
W_{1} & =\frac{0,0024}{0,4724} \\
& =0,0051 \\
W_{2} & =\frac{0,3333}{0,4724} \\
& =0,7057 \\
W_{3} & =\frac{0,07}{0,4724} \\
& =0,1482 \\
W_{4} & =\frac{0,0642}{0,4724} \\
& =0,1359 \\
W_{5} & =\frac{0,0024}{0,4724} \\
& =0,0051
\end{aligned}
$$

Tabel 5. Nilai Bobot Kriteria $\left(W_{j}\right)$

\begin{tabular}{clc}
\hline No & \multicolumn{1}{c}{ Nama Kriteria } & Nilai Bobot (Wj) \\
\hline 1 & PENDIDIKAN (P) & 0,0051 \\
2 & Bidang Keahlian (BK) & 0,7057 \\
3 & Masa Kerja (MK) & 0,1482 \\
4 & NUPTK (N) & 0,1359 \\
5 & Kedisiplinan (K) & 0,0051 \\
& SUM & 1 \\
\hline
\end{tabular}

Setelah mendapatkan nilai bobot untuk setiap kriteria, langkah selanjutnya adalah membuat perangkingan untuk setiap alternatif dengan menggunakan metode Extended Promethee II. Metode Extended Promethee II merupakan pengembangan dari metode promethee II dalam metode ini mengambil keputusan berdasarkan perangkingan atau nilai tertinggi dari suatu alternatif dan berikut ini langkah-langkah dalam penyelesaiannya:

1. Membuat Matriks Keputusan

$\left[\begin{array}{ccccc}4 & 1 & 35 & 1 & 4 \\ 5 & 0 & 11 & 1 & 5 \\ 4 & 1 & 10 & 1 & 4 \\ 4 & 0 & 8 & 0 & 4 \\ 4 & 1 & 11 & 1 & 4 \\ 5 & 0 & 14 & 1 & 4 \\ 4 & 0 & 8 & 1 & 4 \\ 4 & 1 & 11 & 1 & 5\end{array}\right]$

Dimana Max $(\mathrm{Xij})=\mathrm{C} 1=5, \mathrm{C} 2=1, \mathrm{C} 3=35, \mathrm{C} 4=1, \mathrm{C} 5=5$

$$
\operatorname{Min}(\mathrm{Xij})=\mathrm{C} 1=4, \mathrm{C} 2=0, \mathrm{C} 3=8, \mathrm{C} 4=0, \mathrm{C} 5=4
$$

2. Normalisasi Matriks Keputusan

Normalisasi matriks keputusan didapat dari nilai alternatif berdasarkan setiap kriteria dikurang dengan nilai kriteria terendah dan dibagi dengan nilai kriteria tertinggi dikurang dengan nilai kriteria terendah setiap kolom.

$\mathrm{C} 1=$ Pendidikan

$R_{11}=\frac{[4-4]}{[5-4]}=0$

$R_{21}=\frac{[5-4]}{[5-4]}=1$

$R_{31}=\frac{[4-4]}{[5-4]}=0$

$R_{41}=\frac{[4-4]}{[5-4]}=0$

$R_{51}=\frac{[4-4]}{[5-4]}=0$

$R_{61}=\frac{[5-4]}{[5-4]}=1$

$R_{71}=\frac{[4-4]}{[5-4]}=0$

$R_{81}=\frac{[4-4]}{[5-4]}=0$

$\mathrm{C} 2$ = Bidang Keahlian

$R_{12}=\frac{[1-0]}{[1-0]}=1$

$R_{22}=\frac{[0-0]}{[1-0]}=0$

$R_{32}=\frac{[1-0]}{[1-0]}=1$
$R_{42}=\frac{[0-0]}{[1-0]}=0$

$R_{52}=\frac{[1-0]}{[1-0]}=1$

$R_{62}=\frac{[0-0]}{[1-0]}=0$

$R_{72}=\frac{[0-0]}{[1-0]}=0$

$R_{82}=\frac{[1-0]}{[1-0]}=1$

C3 = Masa Kerja

$R_{13}=\frac{[35-8]}{[35-8]}=1$

$R_{23}=\frac{[11-8]}{[35-8]}=0,1111$

$R_{33}=\frac{[10-8]}{[35-8]}=0,0741$

$R_{43}=\frac{[8-8]}{[35-8]}=0$

$R_{53}=\frac{[11-8]}{[35-8]}=0,1111$

$R_{63}=\frac{[14-8]}{[35-8]}=0,2222$ 


$$
\begin{aligned}
& R_{73}=\frac{[8-8]}{[35-8]}=0 \\
& R_{83}=\frac{[11-8]}{[35-8]}=0,1111 \\
& \mathrm{C} 4=\mathrm{NUPTK} \\
& R_{14}=\frac{[1-0]}{[1-0]}=1 \\
& R_{24}=\frac{[1-0]}{[1-0]}=1 \\
& R_{34}=\frac{[1-0]}{[1-0]}=1 \\
& R_{44}=\frac{[0-0]}{[1-0]}=0 \\
& R_{54}=\frac{[5-1]}{[5-1]}=1 \\
& R_{64}=\frac{[1-0]}{[1-0]}=1 \\
& R_{74}=\frac{[1-0]}{[1-0]}=1
\end{aligned}
$$

$$
\begin{aligned}
& R_{84}=\frac{[1-0]}{[1-0]}=1 \\
& \mathrm{C} 5=\text { Kedisiplinan } \\
& R_{15}=\frac{[4-4]}{[5-4]}=0 \\
& R_{25}=\frac{[5-4]}{[5-4]}=1 \\
& R_{35}=\frac{[4-4]}{[5-4]}=0 \\
& R_{45}=\frac{[4-4]}{[5-4]}=0 \\
& R_{55}=\frac{[4-4]}{[5-4]}=0 \\
& R_{65}=\frac{[4-4]}{[5-4]}=0 \\
& R_{75}=\frac{[4-4]}{[5-4]}=0 \\
& R_{25}=\frac{[5-4]}{[5-4]}=1
\end{aligned}
$$

Matriks keputusan yang ternormalisasi dibuat dari hasil normalisasi di atas

$\left[\begin{array}{llcll}0 & 1 & 1 & 1 & 0 \\ 1 & 0 & 0,1111 & 1 & 1 \\ 0 & 1 & 0,0741 & 1 & 0 \\ 0 & 0 & 0 & 0 & 0 \\ 0 & 1 & 0,1111 & 1 & 0 \\ 1 & 0 & 0,2222 & 1 & 0 \\ 0 & 0 & 0 & 1 & 0 \\ 0 & 1 & 0,1111 & 1 & 1\end{array}\right]$

3. Menentukan nilai Preferensi $P j\left(i, i^{\prime}\right)$

$\mathrm{C} 1=$ Pendidikan

If $0 \leq 1$ true, then $\mathrm{P} 1(1,2)=0$

If $0 \leq 0$ true, then $\mathrm{P} 1(1,3)=0$

If $0 \leq 0$ true, then $\mathrm{P} 1(1,4)=0$

If $0 \leq 0$ true, then $\mathrm{P} 1(1,5)=0$

If $0 \leq 1$ true, then $\mathrm{P} 1(1,6)=0$

If $0 \leq 0$ true, then $\mathrm{P} 1(1,7)=0$

If $0 \leq 0$ true, then $\mathrm{P} 1(1,8)=0$

If $1 \leq 0$ false, else if $1>0$ true, then $\mathrm{P} 1(2,1)=1-0=1$

If $1 \leq 0$ false, else if $1>0$ true, then $\mathrm{P} 1(2,3)=1-0=1$

If $1 \leq 0$ false, else if $1>0$ true, then $\mathrm{P} 1(2,4)=1-0=1$

If $1 \leq 0$ false, else if $1>0$ true, then $\mathrm{P} 1(2,5)=1-0=1$

If $1 \leq 1$ true, then $\mathrm{P} 1(2,6)=1$

If $1 \leq 0$ false, else if $1>0$ true, then $\mathrm{P} 1(2,7)=1-0=1$

If $1 \leq 0$ false, else if $1>0$ true, then $\mathrm{P} 1(2,8)=1-0=1$

If $0 \leq 0$ true, then $\mathrm{P} 1(3,1)=0$

If $0 \leq 1$ true, then $\mathrm{P} 1(3,2)=0$

If $0 \leq 0$ true, then $\mathrm{P} 1(3,4)=0$

If $0 \leq 0$ true, then $\mathrm{P} 1(3,5)=0$

If $0 \leq 1$ true, then $\mathrm{P} 1(3,6)=0$

If $0 \leq 0$ true, then $\mathrm{P} 1(3,7)=0$

If $0 \leq 0$ true, then $\mathrm{P} 1(3,8)=0$

If $0 \leq 0$ true, then $\mathrm{P} 1(4,1)=0$

If $0 \leq 1$ true, then $\mathrm{P} 1(4,2)=0$

If $0 \leq 0$ true, then $\mathrm{P} 1(4,3)=0$

If $0 \leq 0$ true, then $\mathrm{P} 1(4,5)=0$

If $0 \leq 1$ true, then $\mathrm{P} 1(4,6)=0$

If $0 \leq 0$ true, then $\mathrm{P} 1(4,7)=0$

If $0 \leq 0$ true, then $\mathrm{P} 1(4,8)=0$

If $0 \leq 0$ true, then $\mathrm{P} 1(5,1)=0$

If $0 \leq 1$ true, then $\mathrm{P} 1(5,2)=0$

If $0 \leq 0$ true, then $\mathrm{P} 1(5,3)=0$

If $0 \leq 0$ true, then $\mathrm{P} 1(5,4)=0$

If $0 \leq 1$ true, then $\mathrm{P} 1(5,6)=0$ 
If $0 \leq 0$ true, then $\mathrm{P} 1(5,7)=0$

If $0 \leq 0$ true, then $\mathrm{P} 1(5,8)=0$

If $1 \leq 0$ false, else if $1>0$ true, then $\mathrm{P} 1(6,1)=1-0=1$

If $1 \leq 1$ true, then $\mathrm{P} 1(6,2)=1$

If $1 \leq 0$ false, else if $1>0$ true, then $\mathrm{P} 1(6,3)=1-0=1$

If $1 \leq 0$ false, else if $1>0$ true, then $\mathrm{P} 1(6,4)=1-0=1$

If $1 \leq 0$ false, else if $1>0$ true, then $\mathrm{P} 1(6,5)=1-0=1$

If $1 \leq 0$ false, else if $1>0$ true, then $\mathrm{P} 1(6,7)=1-0=1$

If $1 \leq 0$ false, else if $1>0$ true, then $\mathrm{P} 1(6,8)=1-0=1$

If $0 \leq 0$ true, then $\mathrm{P} 1(7,1)=0$

If $0 \leq 1$ true, then $\mathrm{P} 1(7,2)=0$

If $0 \leq 0$ true, then $\mathrm{P} 1(7,3)=0$

If $0 \leq 0$ true, then $\mathrm{P} 1(7,4)=0$

If $0 \leq 0$ true, then $\mathrm{P} 1(7,5)=0$

If $0 \leq 1$ true, then $\mathrm{P} 1(7,6)=0$

If $0 \leq 0$ true, then $\mathrm{P} 1(7,8)=0$

If $0 \leq 0$ true, then $\mathrm{P} 1(8,1)=0$

If $0 \leq 1$ true, then $\mathrm{P} 1(8,2)=0$

If $0 \leq 0$ true, then $\mathrm{P} 1(8,3)=0$

If $0 \leq 0$ true, then $\mathrm{P} 1(8,4)=0$

If $0 \leq 0$ true, then $\mathrm{P} 1(8,5)=0$

If $0 \leq 1$ true, then $\mathrm{P} 1(8,6)=0$

If $0 \leq 0$ true, then $\mathrm{P} 1(8,7)=0$

$\mathrm{C} 2$ = Bidang Keahlian

If $1 \leq 0$ false, else if $1>0$ true, then $\mathrm{P} 2(1,2)=1-0=1$

If $1 \leq 1$ true, then $\mathrm{P} 2(1,3)=1$

If $1 \leq 0$ false, else if $1>0$ true, then $\mathrm{P} 2(1,4)=1-0=1$

If $1 \leq 1$ true, then $\mathrm{P} 2(1,5)=1$

If $1 \leq 0$ false, else if $1>0$ true, then $\mathrm{P} 2(1,6)=1-0=1$

If $1 \leq 0$ false, else if $1>0$ true, then $\mathrm{P} 2(1,7)=1-0=1$

If $1 \leq 1$ true, then $\mathrm{P} 2(1,8)=1$

If $0 \leq 1$ true, then $\mathrm{P} 2(2,1)=0$

If $0 \leq 1$ true, then $\mathrm{P} 2(2,3)=0$

If $0 \leq 0$ true, then $\mathrm{P} 2(2,4)=0$

If $0 \leq 1$ true, then $\mathrm{P} 2(2,5)=0$

If $0 \leq 0$ true, then $\mathrm{P} 2(2,6)=0$

If $0 \leq 0$ true, then $\mathrm{P} 2(2,7)=0$

If $0 \leq 1$ true, then $\mathrm{P} 2(2,8)=0$

If $1 \leq 1$ true, then $\mathrm{P} 2(3,1)=1$

If $1 \leq 0$ false, else if $1>0$ true, then $\mathrm{P} 2(3,2)=1-0=1$

If $1 \leq 0$ false, else if $1>0$ true, then $\mathrm{P} 2(3,4)=1-0=1$

If $1 \leq 1$ true, then $\mathrm{P} 2(3,5)=1$

If $1 \leq 0$ false, else if $1>0$ true, then $\mathrm{P} 2(3,6)=1-0=1$ If $1 \leq 0$ false, else if $1>0$ true, then $\mathrm{P} 2(3,7)=1-0=1$

If $1 \leq 1$ true, then $\mathrm{P} 2(3,8)=1$

If $0 \leq 1$ true, then $\mathrm{P} 2(4,1)=0$

If $0 \leq 0$ true, then $\mathrm{P} 2(4,2)=0$

If $0 \leq 1$ true, then $\mathrm{P} 2(4,3)=0$

If $0 \leq 1$ true, then $\mathrm{P} 2(4,5)=0$

If $0 \leq 0$ true, then $\mathrm{P} 2(4,6)=0$

If $0 \leq 0$ true, then $\mathrm{P} 2(4,7)=0$

If $0 \leq 1$ true, then $\mathrm{P} 2(4,8)=0$

If $1 \leq 1$ true, then $\mathrm{P} 2(5,1)=1$

If $1 \leq 0$ false, else if $1>0$ true, then $\mathrm{P} 2(5,2)=1-0=1$ If $1 \leq 1$ true, then $\mathrm{P} 2(5,3)=1$

If $1 \leq 0$ false, else if $1>0$ true, then $\mathrm{P} 2(5,4)=1-0=1$

If $1 \leq 0$ false, else if $1>0$ true, then $\mathrm{P} 2(5,6)=1-0=1$

If $1 \leq 0$ false, else if $1>0$ true, then $\mathrm{P} 2(5,7)=1-0=1$

If $1 \leq 1$ true, then $\mathrm{P} 2(5,8)=1$

If $0 \leq 1$ true, then $\mathrm{P} 2(6,1)=0$ 


\section{Journal of Computer System and Informatics (JoSYC)}

Volume 3, No. 1, November 2021, Page 26-56

ISSN 2714-8912 (media online)

ISSN 2714-7150 (media cetak)

DOI 10.47065/josyc.v3i1.821

If $0 \leq 0$ true, then $\mathrm{P} 2(6,2)=0$

If $0 \leq 1$ true, then $\mathrm{P} 2(6,3)=0$

If $0 \leq 0$ true, then $\mathrm{P} 2(6,4)=0$

If $0 \leq 1$ true, then $\mathrm{P} 2(6,5)=0$

If $0 \leq 0$ true, then $\mathrm{P} 2(6,7)=0$

If $0 \leq 1$ true, then $\mathrm{P} 2(6,8)=0$

If $0 \leq 1$ true, then $\mathrm{P} 2(7,1)=0$

If $0 \leq 0$ true, then $\mathrm{P} 2(7,2)=0$

If $0 \leq 1$ true, then $\mathrm{P} 2(7,3)=0$

If $0 \leq 0$ true, then $\mathrm{P} 2(7,4)=0$

If $0 \leq 1$ true, then $\mathrm{P} 2(7,5)=0$

If $0 \leq 0$ true, then $\mathrm{P} 2(7,6)=0$

If $0 \leq 1$ true, then $\mathrm{P} 2(7,8)=0$

If $1 \leq 1$ true, then $\mathrm{P} 2(8,1)=1$

If $1 \leq 0$ false, else if $1>0$ true, then $\mathrm{P} 2(8,2)=1-0=1$

If $1 \leq 1$ true, then $\mathrm{P} 2(8,3)=1$

If $1 \leq 0$ false, else if $1>0$ true, then $\mathrm{P} 2(8,4)=1-0=1$

If $1 \leq 1$ true, then $\mathrm{P} 2(8,5)=1$

If $1 \leq 0$ false, else if $1>0$ true, then $\mathrm{P} 2(8,6)=1-0=1$

If $1 \leq 0$ false, else if $1>0$ true, then $\mathrm{P} 2(8,7)=1-0=1$

C3= Masa Kerja

If $1 \leq 0,1111$ false, else if $1>0,1111$ true, then $\mathrm{P} 3(1,2)=1-0,1111=0,8889$

If $1 \leq 0,0741$ false, else if $1>0,0741$ true, then $\mathrm{P} 3(1,3)=1-0,0741=0,9259$

If $1 \leq 0$ false, else if $1>0$ true, then $\mathrm{P} 3(1,4)=1-0=1$

If $1 \leq 0,1111$ false, else if $1>0,1111$ true, then $\mathrm{P} 3(1,5)=1-0,1111=0,8889$

If $1 \leq 0,1111$ false, else if $1>0,2222$ true, then $\mathrm{P} 3(1,6)=1-0,2222=0,7778$

If $1 \leq 0$ false, else if $1>0$ true, then $\mathrm{P} 3(1,7)=1-0=1$

If $1 \leq 0,1111$ false, else if $1>0,1111$ true, then $\mathrm{P} 3(1,8)=1-0,1111=0,8889$

If $0,1111 \leq 1$ true, then $\mathrm{P} 3(2,1)=0,1111$

If $0,1111 \leq 0,0741$ false, else if $0,1111>0,0741$ true, then $\mathrm{P} 3(2,3)=0,1111-0,0741=0,0370$

If $0,1111 \leq 0$ false, else if $0,1111>0$ true, then $\mathrm{P} 3(2,4)=0,1111-0=0,1111$

If $0,1111 \leq 0,1111$ true, then $\mathrm{P} 3(2,5)=0,1111$

If $0,1111 \leq 0,2222$ true, then $\mathrm{P} 3(2,6)=0,1111$

If $0,1111 \leq 0$ false, else if $0,1111>0$ true, then $\mathrm{P} 3(2,7)=0,1111-0=0,1111$

If $0,1111 \leq 0,1111$ true, then $\mathrm{P} 3(2,8)=0,1111$

If $0,0741 \leq 1$ true, then $\mathrm{P} 3(3,1)=0,0741$

If $0,0741 \leq 0,1111$ true, then $\mathrm{P} 3(3,2)=0,0741$

If $0,0741 \leq 0$ false, else if $0,0741>0$ true, then $\mathrm{P} 3(3,4)=0,0741-0=0,0741$

If $0,0741 \leq 0,1111$ true, then $\mathrm{P} 3(3,5)=0,0741$

If $0,0741 \leq 0,2222$ true, then $\mathrm{P} 3(3,6)=0,0741$

If $0,0741 \leq 0$ false, else if $0,0741>0$ true, then $\mathrm{P} 3(3,7)=0,0741-0=0,0741$

If $0,0741 \leq 0,1111$ true, then $\mathrm{P} 3(3,8)=0,0741$

If $0 \leq 1$ true, then $\mathrm{P} 3(4,1)=0$

If $0 \leq 0,1111$ true, then $\mathrm{P} 3(4,2)=0$

If $0 \leq 0,0741$ true, then $\mathrm{P} 3(4,3)=0$

If $0 \leq 0,1111$ true, then $\mathrm{P} 3(4,5)=0$

If $0 \leq 0,2222$ true, then $\mathrm{P} 3(4,6)=0$

If $0 \leq 0$ true, then $\mathrm{P} 3(4,7)=0$

If $0 \leq 0,1111$ true, then $\mathrm{P} 3(4,8)=0$

If $0,1111 \leq 1$ true, then $\mathrm{P} 3(5,1)=0,1111$

If $0,1111 \leq 0,1111$ true, then $\mathrm{P} 3(5,2)=0,1111$

If $0,1111 \leq 0,0741$ false, else if $0,1111>0,0741$ true, then $\mathrm{P} 3(5,3)=0,1111-0,0741=0,0370$

If $0,1111 \leq 0$ false, else if $0,1111>0$ true, then $\mathrm{P} 3(5,4)=0,1111-0=0,1111$

If $0,1111 \leq 0,2222$ true, then $\mathrm{P} 3(5,6)=0,1111$

If $0,1111 \leq 0$ false, else if $0,1111>0$ true, then $\mathrm{P} 3(5,7)=0,1111-0=0,1111$

If $0,1111 \leq 0,1111$ true, then $\mathrm{P} 3(5,8)=0,1111$

If $0,2222 \leq 1$ true, then $\mathrm{P} 3(6,1)=0,2222$

If $0,2222 \leq 0,1111$ false, else if $0,2222>0,1111$ true, then $\mathrm{P} 3(6,2)=0,2222-0,1111=0,1111$

If $0,2222 \leq 0,0741$ false, else if $0,2222>0,0741$ true, then $\mathrm{P} 3(6,3)=0,2222-0,0741=0,1481$

If $0,2222 \leq 0$ false, else if $0,2222>0$ true, then $\mathrm{P} 3(6,4)=0,2222-0=0,2222$ 


\section{Journal of Computer System and Informatics (JoSYC)}

Volume 3, No. 1, November 2021, Page 26-56

ISSN 2714-8912 (media online)

ISSN 2714-7150 (media cetak)

DOI 10.47065/josyc.v3i1.821

If $0,2222 \leq 0,1111$ false, else if $0,2222>0,1111$ true, then $\mathrm{P} 3(6,5)=0,2222-0,1111=0,1111$

If $0,2222 \leq 0$ false, else if $0,2222>0$ true, then $\mathrm{P} 3(6,7)=0,2222-0=0,2222$

If $0,2222 \leq 0,1111$ false, else if $0,2222>0,1111$ true, then $\mathrm{P} 3(6,8)=0,2222-0,1111=0,1111$

If $0 \leq 1$ true, then $\mathrm{P} 3(7,1)=0$

If $0 \leq 0,1111$ true, then $\mathrm{P} 3(7,2)=0$

If $0 \leq 0,0741$ true, then $\mathrm{P} 3(7,3)=0$

If $0 \leq 0$ true, then $\mathrm{P} 3(7,4)=0$

If $0 \leq 0,1111$ true, then $\mathrm{P} 3(7,5)=0$

If $0 \leq 0,2222$ true, then $\mathrm{P} 3(7,6)=0$

If $0 \leq 0,1111$ true, then $\mathrm{P} 3(7,8)=0$

If $0,1111 \leq 1$ true, then $\mathrm{P} 3(8,1)=0,1111$

If $0,1111 \leq 0,1111$ true, then $\mathrm{P} 3(8,2)=0,1111$

If $0,1111 \leq 0,0741$ false, else if $0,1111>0,0741$ true, then $\mathrm{P} 3(8,3)=0,1111-0,0741=0,0370$

If $0,1111 \leq 0$ false, else if $0,1111>0$ true, then $\mathrm{P} 3(8,4)=0,1111-0=0,1111$

If $0,1111 \leq 0,1111$ true, then $\mathrm{P} 3(8,5)=0,1111$

If $0,1111 \leq 0,2222$ true, then $\mathrm{P} 3(8,6)=0,1111$

If $0,1111 \leq 0$ false, else if $0,1111>0$ true, then $\mathrm{P} 3(8,7)=0,1111-0=0,1111$

\section{$\mathrm{C} 4=$ NUPTK}

If $1 \leq 1$ true, then $\mathrm{P} 4(1,2)=0$

If $1 \leq 1$ true, then $\mathrm{P} 4(1,3)=0$

If $1 \leq 0$ false, else if $1>0$ true, then $\mathrm{P} 4(1,4)=1-0=1$

If $1 \leq 1$ true, then $\mathrm{P} 4(1,5)=0$

If $1 \leq 1$ true, then $\mathrm{P} 4(1,6)=0$

If $1 \leq 1$ true, then $\mathrm{P} 4(1,7)=0$

If $1 \leq 1$ true, then $\mathrm{P} 4(1,8)=0$

If $1 \leq 1$ true, then $\mathrm{P} 4(2,1)=0$

If $1 \leq 1$ true, then $\mathrm{P} 4(2,3)=0$

If $1 \leq 0$ false, else if $1>0$ true, then $\mathrm{P} 4(2,4)=1-0=1$

If $1 \leq 1$ true, then $\mathrm{P} 4(2,5)=0$

If $1 \leq 1$ true, then $\mathrm{P} 4(2,6)=0$

If $1 \leq 1$ true, then $\mathrm{P} 4(2,7)=0$

If $1 \leq 1$ true, then $\mathrm{P} 4(2,8)=0$

If $1 \leq 1$ true, then $\mathrm{P} 4(3,1)=0$

If $1 \leq 1$ true, then $\mathrm{P} 4(3,2)=0$

If $1 \leq 0$ false, else if $1>0$ true, then $\mathrm{P} 4(3,4)=1-0=1$

If $1 \leq 1$ true, then $\mathrm{P} 4(3,5)=0$

If $1 \leq 1$ true, then $\mathrm{P} 4(3,6)=0$

If $1 \leq 1$ true, then $\mathrm{P} 4(3,7)=0$

If $1 \leq 1$ true, then $\mathrm{P} 4(3,8)=0$

If $0 \leq 1$ true, then $\mathrm{P} 4(4,1)=0$

If $0 \leq 1$ true, then $\mathrm{P} 4(4,2)=0$

If $0 \leq 1$ true, then $\mathrm{P} 4(4,3)=0$

If $0 \leq 1$ true, then $\mathrm{P} 4(4,5)=0$

If $0 \leq 1$ true, then $\mathrm{P} 4(4,6)=0$

If $0 \leq 1$ true, then $\mathrm{P} 4(4,7)=0$

If $0 \leq 1$ true, then $\mathrm{P} 4(4,8)=0$

If $1 \leq 1$ true, then $\mathrm{P} 4(5,1)=0$

If $1 \leq 1$ true, then $\mathrm{P} 4(5,2)=0$

If $1 \leq 1$ true, then $\mathrm{P} 4(5,3)=0$

If $1 \leq 0$ false, else if $1>0$ true, then $\mathrm{P} 4(5,4)=1-0=1$

If $1 \leq 1$ true, then $\mathrm{P} 4(5,6)=0$

If $1 \leq 1$ true, then $\mathrm{P} 4(5,7)=0$

If $1 \leq 1$ true, then $\mathrm{P} 4(5,8)=0$

If $1 \leq 1$ true, then $\mathrm{P} 4(6,1)=0$

If $1 \leq 1$ true, then $\mathrm{P} 4(6,2)=0$

If $1 \leq 1$ true, then $\mathrm{P} 4(6,3)=0$

If $1 \leq 0$ false, else if $1>0$ true, then $\mathrm{P} 4(6,4)=1-0=1$

If $1 \leq 1$ true, then $\mathrm{P} 4(6,5)=0$

If $1 \leq 1$ true, then $\mathrm{P} 4(6,7)=0$

If $1 \leq 1$ true, then $\mathrm{P} 4(6,8)=0$ 
If $1 \leq 1$ true, then $\mathrm{P} 4(7,1)=0$

If $1 \leq 1$ true, then $\mathrm{P} 4(7,2)=0$

If $1 \leq 1$ true, then $\mathrm{P} 4(7,3)=0$

If $1 \leq 0$ false, else if $1>0$ true, then $\mathrm{P} 4(7,4)=1-0=1$

If $1 \leq 1$ true, then $\mathrm{P} 4(7,5)=0$

If $1 \leq 1$ true, then $\mathrm{P} 4(7,6)=0$

If $1 \leq 1$ true, then $\mathrm{P} 4(7,8)=0$

If $1 \leq 1$ true, then $\mathrm{P} 4(8,1)=0$

If $1 \leq 1$ true, then $\mathrm{P} 4(8,2)=0$

If $1 \leq 1$ true, then $\mathrm{P} 4(8,3)=0$

If $1 \leq 0$ false, else if $1>0$ true, then $\mathrm{P} 4(8,4)=1-0=1$

If $1 \leq 1$ true, then $\mathrm{P} 4(8,5)=0$

If $1 \leq 1$ true, then $\mathrm{P} 4(8,6)=0$

If $1 \leq 1$ true, then $\mathrm{P} 4(8,7)=0$

C5 = Kedisiplinan

If $0 \leq 1$ true, then $\mathrm{P} 5(1,2)=0$

If $0 \leq 0$ true, then $\mathrm{P} 5(1,3)=0$

If $0 \leq 0$ true, then $\mathrm{P} 5(1,4)=0$

If $0 \leq 0$ true, then $\mathrm{P} 5(1,5)=0$

If $0 \leq 0$ true, then $\mathrm{P} 5(1,6)=0$

If $0 \leq 0$ true, then $\mathrm{P} 5(1,7)=0$

If $0 \leq 1$ true, then $\mathrm{P} 5(1,8)=0$

If $1 \leq 0$ false, else if $1>0$ true, then $\mathrm{P} 5(2,1)=1-0=1$ If $1 \leq 0$ false, else if $1>0$ true, then $\mathrm{P} 5(2,3)=1-0=1$ If $1 \leq 0$ false, else if $1>0$ true, then $\mathrm{P} 5(2,4)=1-0=1$ If $1 \leq 0$ false, else if $1>0$ true, then $\mathrm{P} 5(2,5)=1-0=1$ If $1 \leq 0$ false, else if $1>0$ true, then $\mathrm{P} 5(2,6)=1-0=1$ If $1 \leq 0$ false, else if $1>0$ true, then $\mathrm{P} 5(2,7)=1-0=1$

If $1 \leq 1$ true, then $\mathrm{P} 5(2,8)=1$

If $0 \leq 0$ true, then $\mathrm{P} 5(3,1)=0$

If $0 \leq 2$ true, then $\mathrm{P} 5(3,2)=0$

If $0 \leq 0$ true, then $\mathrm{P} 5(3,4)=0$

If $0 \leq 0$ true, then $\mathrm{P} 5(3,5)=0$

If $0 \leq 0$ true, then $\mathrm{P} 5(3,6)=0$

If $0 \leq 0$ true, then $\mathrm{P} 5(3,7)=0$

If $0 \leq 1$ true, then $\mathrm{P} 5(3,8)=0$

If $0 \leq 0$ true, then $\mathrm{P} 5(4,1)=0$

If $0 \leq 2$ true, then $\mathrm{P} 5(4,2)=0$

If $0 \leq 0$ true, then $\mathrm{P} 5(4,3)=0$

If $0 \leq 0$ true, then $\mathrm{P} 5(4,5)=0$

If $0 \leq 0$ true, then $\mathrm{P} 5(4,6)=0$

If $0 \leq 0$ true, then $\mathrm{P} 5(4,7)=0$

If $0 \leq 1$ true, then $\mathrm{P} 5(4,8)=0$

If $0 \leq 0$ true, then $\mathrm{P} 5(5,1)=0$

If $0 \leq 2$ true, then $\mathrm{P} 5(5,2)=0$

If $0 \leq 0$ true, then $\mathrm{P} 5(5,3)=0$

If $0 \leq 0$ true, then $\mathrm{P} 5(5,4)=0$

If $0 \leq 0$ true, then $\mathrm{P} 5(5,6)=0$

If $0 \leq 0$ true, then $\mathrm{P} 5(5,7)=0$

If $0 \leq 1$ true, then $\mathrm{P} 5(5,8)=0$

If $0 \leq 0$ true, then P5(6,1) $=0$

If $0 \leq 2$ true, then $\mathrm{P} 5(6,2)=0$

If $0 \leq 0$ true, then $\mathrm{P} 5(6,3)=0$

If $0 \leq 0$ true, then $\mathrm{P} 5(6,4)=0$

If $0 \leq 0$ true, then $\mathrm{P} 5(6,5)=0$

If $0 \leq 0$ true, then $\mathrm{P} 5(6,7)=0$

If $0 \leq 1$ true, then $\mathrm{P} 5(6,8)=0$

If $0 \leq 0$ true, then $\mathrm{P} 5(7,1)=0$

If $0 \leq 2$ true, then $\mathrm{P} 5(7,2)=0$

If $0 \leq 0$ true, then $\mathrm{P} 5(7,3)=0$ 
Selanjutnya hasil nilai preferensi dibuat menjadi data dalam bentuk tabel.

Tabel 6. Nilai Preferensi

\begin{tabular}{|c|c|c|c|c|c|}
\hline Alternatif & MK & $P$ & $\mathrm{~L}$ & PK & $\mathrm{D}$ \\
\hline $\operatorname{Pj}(1,2)$ & 0 & 1 & 0,8889 & 1 & 0 \\
\hline $\mathrm{Pj}(1,3)$ & 0 & 1 & 0,9259 & 1 & 0 \\
\hline $\operatorname{Pj}(1,4)$ & 0 & 1 & 1 & 1 & 0 \\
\hline $\mathrm{Pj}(1,5)$ & 0 & 1 & 0,8889 & 1 & 0 \\
\hline $\mathrm{Pj}(1,6)$ & 0 & 1 & 0,7778 & 1 & 0 \\
\hline $\mathrm{Pj}(1,7)$ & 0 & 1 & 1 & 1 & 0 \\
\hline $\mathrm{Pj}(1,8)$ & 0 & 1 & 0,8889 & 1 & 0 \\
\hline $\mathrm{Pj}(2,1)$ & 1 & 0 & 0,1111 & 1 & 1 \\
\hline $\operatorname{Pj}(2,3)$ & 1 & 0 & 0,0370 & 1 & 1 \\
\hline $\operatorname{Pj}(2,4)$ & 1 & 0 & 0,1111 & 1 & 1 \\
\hline $\operatorname{Pj}(2,5)$ & 1 & 0 & 0,1111 & 1 & 1 \\
\hline $\operatorname{Pj}(2,6)$ & 1 & 0 & 0,1111 & 1 & 1 \\
\hline $\operatorname{Pj}(2,7)$ & 1 & 0 & 0,1111 & 1 & 1 \\
\hline $\mathrm{Pj}(2,8)$ & 1 & 0 & 0,1111 & 1 & 1 \\
\hline $\mathrm{Pj}(3,1)$ & 0 & 1 & 0,0741 & 1 & 0 \\
\hline $\operatorname{Pj}(3,2)$ & 0 & 1 & 0,0741 & 1 & 0 \\
\hline $\mathrm{Pj}(3,4)$ & 0 & 1 & 0,0741 & 1 & 0 \\
\hline $\operatorname{Pj}(3,5)$ & 0 & 1 & 0,0741 & 1 & 0 \\
\hline $\mathrm{Pj}(3,6)$ & 0 & 1 & 0,0741 & 1 & 0 \\
\hline $\operatorname{Pj}(3,7)$ & 0 & 1 & 0,0741 & 1 & 0 \\
\hline $\operatorname{Pj}(3,8)$ & 0 & 1 & 0,0741 & 1 & 0 \\
\hline $\mathrm{Pj}(4,1)$ & 0 & 0 & 0 & 0 & 0 \\
\hline $\mathrm{Pj}(4,2)$ & 0 & 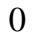 & 0 & 0 & 0 \\
\hline $\mathrm{Pj}(4,3)$ & 0 & 0 & 0 & 0 & 0 \\
\hline $\mathrm{Pj}(4,5)$ & 0 & 0 & 0 & 0 & 0 \\
\hline $\mathrm{Pj}(4,6)$ & 0 & 0 & 0 & 0 & 0 \\
\hline $\mathrm{Pj}(4,7)$ & 0 & 0 & 0 & 0 & 0 \\
\hline $\mathrm{Pj}(4,8)$ & 0 & 0 & 0 & 0 & 0 \\
\hline $\operatorname{Pj}(5,1)$ & 0 & 1 & 0,1111 & 1 & 0 \\
\hline $\operatorname{Pj}(5,2)$ & 0 & 1 & 0,1111 & 1 & 0 \\
\hline $\mathrm{Pj}(5,3)$ & 0 & 1 & 0,0370 & 1 & 0 \\
\hline $\operatorname{Pj}(5,4)$ & 0 & 1 & 0,1111 & 1 & 0 \\
\hline $\mathrm{Pj}(5,6)$ & 0 & 1 & 0,1111 & 1 & 0 \\
\hline $\mathrm{Pj}(5,7)$ & 0 & 1 & 0,1111 & 1 & 0 \\
\hline $\mathrm{Pj}(5,8)$ & 0 & 1 & 0,1111 & 1 & 0 \\
\hline $\mathrm{Pj}(6,1)$ & 1 & 0 & 0,2222 & 1 & 0 \\
\hline $\mathrm{Pj}(6,2)$ & 1 & 0 & 0,1111 & 1 & 0 \\
\hline $\operatorname{Pj}(6,3)$ & 1 & 0 & 0,1481 & 1 & 0 \\
\hline $\mathrm{Pj}(6,4)$ & 1 & 0 & 0,2222 & 1 & 0 \\
\hline $\mathrm{Pj}(6,5)$ & 1 & 0 & 0,1111 & 1 & 0 \\
\hline $\operatorname{Pj}(6,7)$ & 1 & 0 & 0,2222 & 1 & 0 \\
\hline $\mathrm{Pj}(6,8)$ & 1 & 0 & 0,1111 & 1 & 0 \\
\hline $\operatorname{Pj}(7,1)$ & 0 & 0 & 0 & 1 & 0 \\
\hline $\mathrm{Pj}(7,2)$ & 0 & 0 & 0 & 1 & 0 \\
\hline $\operatorname{Pj}(7,3)$ & 0 & 0 & 0 & 1 & 0 \\
\hline $\mathrm{Pj}(7,4)$ & 0 & 0 & 0 & 1 & 0 \\
\hline
\end{tabular}




\begin{tabular}{cccccc}
\hline Alternatif & MK & P & L & PK & D \\
\hline $\operatorname{Pj}(7,5)$ & 0 & 0 & 0 & 1 & 0 \\
$\operatorname{Pj}(7,6)$ & 0 & 0 & 0 & 1 & 0 \\
$\operatorname{Pj}(7,8)$ & 0 & 0 & 0 & 1 & 0 \\
$\operatorname{Pj}(8,1)$ & 0 & 1 & 0,1111 & 1 & 1 \\
$\operatorname{Pj}(8,2)$ & 0 & 1 & 0,1111 & 1 & 1 \\
$\operatorname{Pj}(8,3)$ & 0 & 1 & 0,0370 & 1 & 1 \\
$\operatorname{Pj}(8,4)$ & 0 & 1 & 0,1111 & 1 & 1 \\
$\operatorname{Pj}(8,5)$ & 0 & 1 & 0,1111 & 1 & 1 \\
$\operatorname{Pj}(8,6)$ & 0 & 1 & 0,1111 & 1 & 1 \\
$\operatorname{Pj}(8,7)$ & 0 & 1 & 0,1111 & 1 & 1 \\
\hline
\end{tabular}

4. Menghitung nilai $W P\left(i, i^{\prime}\right)$

Nilai WP(i,i')merupakan penjumlahan dari setiap hasil perkalian nilai yang dimiliki kriteria dengan jumlah bobot yang sudah ditentukan sebelumnya. Hal ini sesuai dengan persamaan 3.5 pada bab sebelumnya.

$$
\begin{aligned}
& W P(i, i)=\left[\sum_{j=1}^{n} W_{j} x P_{j}(i, i)\right] / \sum_{j=1}^{n} W_{j} \\
&=\frac{\left[\left(W_{1} x P_{1}(1,2)\right)+\left(W_{2} x P_{2}(1,2)\right)+\left(W_{3} x P_{3}(1,2)\right)+\left(W_{4} x P_{4}(1,2)\right)+\left(W_{5} x P_{5}(1,2)\right]\right.}{1} \\
&=\frac{[(0,0051 * 0)+(0,7057 * 1)+(0,1482 * 0,8889)+(0,1359 * 1)+(0,0051 * 0)]}{1} \\
& W P(1,2)=0,9733 \\
&=\frac{\left[\left(W_{1} x P_{1}(1,3)\right)+\left(W_{2} x P_{2}(1,3)\right)+\left(W_{3} x P_{3}(1,3)\right)+\left(W_{4} x P_{4}(1,3)\right)+\left(W_{5} x P_{5}(1,3)\right]\right.}{1} \\
&=\frac{[(0,0051 * 0)+(0,7057 * 1)+(0,1482 * 0,9259)+(0,1359 * 1)+(0,0051 * 0)]}{1} \\
& W P(1,3)=0,9788 \\
&=\frac{\left[\left(W_{1} x P_{1}(1,4)\right)+\left(W_{2} x P_{2}(1,4)\right)+\left(W_{3} x P_{3}(1,4)\right)+\left(W_{4} x P_{4}(1,4)\right)+\left(W_{5} x P_{5}(1,4)\right]\right.}{1} \\
&= {[(0,0051 * 0)+(0,7057 * 1)+(0,1482 * 1)+(0,1359 * 1)+(0,0051 * 0)] } \\
& W P(1,4)+1
\end{aligned}
$$

$W P(1,4)=0,9898$

$$
\begin{aligned}
& =\frac{\left[\left(W_{1} x P_{1}(1,5)\right)+\left(W_{2} x P_{2}(1,5)\right)+\left(W_{3} x P_{3}(1,5)\right)+\left(W_{4} x P_{4}(1,5)\right)+\left(W_{5} x P_{5}(1,5)\right]\right.}{1} \\
& =\frac{[(0,0051 * 0)+(0,7057 * 1)+(0,1482 * 0,8889)+(0,1359 * 1)+(0,0051 * 0)]}{1}
\end{aligned}
$$

$W P(1,5)=0,9733$

$$
\begin{aligned}
& =\frac{\left[\left(W_{1} x P_{1}(1,6)\right)+\left(W_{2} x P_{2}(1,6)\right)+\left(W_{3} x P_{3}(1,6)\right)+\left(W_{4} x P_{4}(1,6)\right)+\left(W_{5} x P_{5}(1,6)\right]\right.}{1} \\
& =\frac{[(0,0051 * 0)+(0,7057 * 1)+(0,1482 * 0,7778)+(0,1359 * 1)+(0,0051 * 0)]}{1}
\end{aligned}
$$

$W P(1,6)=0,9569$

$$
\begin{aligned}
& =\frac{\left[\left(W_{1} x P_{1}(1,7)\right)+\left(W_{2} x P_{2}(1,7)\right)+\left(W_{3} x P_{3}(1,7)\right)+\left(W_{4} x P_{4}(1,7)\right)+\left(W_{5} x P_{5}(1,7)\right]\right.}{1} \\
& =\frac{[(0,0051 * 0)+(0,7057 * 1)+(0,1482 * 1)+(0,1359 * 1)+(0,0051 * 0)]}{1}
\end{aligned}
$$

$W P(1,7)=0,9898$

$$
\begin{aligned}
& =\frac{\left[\left(W_{1} x P_{1}(1,8)\right)+\left(W_{2} x P_{2}(1,8)\right)+\left(W_{3} x P_{3}(1,8)\right)+\left(W_{4} x P_{4}(1,8)\right)+\left(W_{5} x P_{5}(1,8)\right]\right.}{1} \\
& =\frac{[(0,0051 * 0)+(0,7057 * 1)+(0,1482 * 0,8889)+(0,1359 * 1)+(0,0051 * 0)]}{1}
\end{aligned}
$$

$W P(1,8)=0,9733$

$$
\begin{aligned}
& =\frac{\left[\left(W_{1} x P_{1}(2,1)\right)+\left(W_{2} x P_{2}(2,1)\right)+\left(W_{3} x P_{3}(2,1)\right)+\left(W_{4} x P_{4}(2,1)\right)+\left(W_{5} x P_{5}(2,1)\right]\right.}{1} \\
& =\frac{[(0,0051 * 1)+(0,7057 * 0)+(0,1482 * 0,1111)+(0,1359 * 1)+(0,0051 * 1)]}{1}
\end{aligned}
$$

$W P(2,1)=0,1626$

$$
=\frac{\left[\left(W_{1} x P_{1}(2,3)\right)+\left(W_{2} x P_{2}(2,3)\right)+\left(W_{3} x P_{3}(2,3)\right)+\left(W_{4} x P_{4}(2,3)\right)+\left(W_{5} x P_{5}(2,3)\right]\right.}{1}
$$




\section{Journal of Computer System and Informatics (JoSYC)}

Volume 3, No. 1, November 2021, Page 26-56

ISSN 2714-8912 (media online)

ISSN 2714-7150 (media cetak)

DOI 10.47065/josyc.v3i1.821

$$
\begin{aligned}
& =\frac{[(0,0051 * 1)+(0,7057 * 0)+(0,1482 * 0,0370)+(0,1359 * 1)+(0,0051 * 1)]}{1} \\
& W P(2,3)=0,1516 \\
& =\frac{\left[\left(W_{1} x P_{1}(2,4)\right)+\left(W_{2} x P_{2}(2,4)\right)+\left(W_{3} x P_{3}(2,4)\right)+\left(W_{4} x P_{4}(2,4)\right)+\left(W_{5} x P_{5}(2,4)\right]\right.}{1} \\
& W P(2,4)=0,1626 \\
& =\frac{[(0,0051 * 1)+(0,7057 * 0)+(0,1482 * 0,1111)+(0,1359 * 1)+(0,0051 * 1)]}{1} \\
& =\frac{\left[\left(W_{1} x P_{1}(2,5)\right)+\left(W_{2} x P_{2}(2,5)\right)+\left(W_{3} x P_{3}(2,5)\right)+\left(W_{4} x P_{4}(2,5)\right)+\left(W_{5} x P_{5}(2,5)\right]\right.}{1} \\
& =\frac{[(0,0051 * 1)+(0,7057 * 0)+(0,1482 * 0,1111)+(0,1359 * 1)+(0,0051 * 1)]}{1} \\
& W P(2,5)=0,1626 \\
& \begin{array}{l}
=\frac{\left[\left(W_{1} x P_{1}(2,6)\right)+\left(W_{2} x P_{2}(2,6)\right)+\left(W_{3} x P_{3}(2,6)\right)+\left(W_{4} x P_{4}(2,6)\right)+\left(W_{5} x P_{5}(2,6)\right]\right.}{1} \\
=\frac{[(0,0051 * 1)+(0,7057 * 0)+(0,1482 * 0,1111)+(0,1359 * 1)+(0,0051 * 1)]}{1}
\end{array} \\
& W P(2,6)=0,1626 \\
& \begin{array}{l}
=\frac{\left[\left(W_{1} x P_{1}(2,7)\right)+\left(W_{2} x P_{2}(2,7)\right)+\left(W_{3} x P_{3}(2,7)\right)+\left(W_{4} x P_{4}(2,7)\right)+\left(W_{5} x P_{5}(2,7)\right]\right.}{1} \\
=\frac{[(0,0051 * 1)+(0,7057 * 0)+(0,1482 * 0,1111)+(0,1359 * 1)+(0,0051 * 1)]}{1}
\end{array} \\
& W P(2,7)=0,1626 \\
& \begin{array}{l}
=\frac{\left[\left(W_{1} x P_{1}(2,8)\right)+\left(W_{2} x P_{2}(2,8)\right)+\left(W_{3} x P_{3}(2,8)\right)+\left(W_{4} x P_{4}(2,8)\right)+\left(W_{5} x P_{5}(2,8)\right]\right.}{1} \\
=\frac{[(0,0051 * 1)+(0,7057 * 0)+(0,1482 * 0,1111)+(0,1359 * 1)+(0,0051 * 1)]}{1}
\end{array} \\
& W P(2,8)=0,1626 \\
& \begin{array}{l}
=\frac{\left[\left(W_{1} x P_{1}(3,1)\right)+\left(W_{2} x P_{2}(3,1)\right)+\left(W_{3} x P_{3}(3,1)\right)+\left(W_{4} x P_{4}(3,1)\right)+\left(W_{5} x P_{5}(3,1)\right]\right.}{1} \\
=\frac{[(0,0051 * 0)+(0,7057 * 1)+(0,1482 * 0,0741)+(0,1359 * 1)+(0,0051 * 0)]}{1}
\end{array}
\end{aligned}
$$

\begin{tabular}{|c|c|}
\hline Alternatif & Nilai \\
\hline $\mathrm{WP}(1,2)$ & 0,9733 \\
\hline $\mathrm{WP}(1,3)$ & 0,9788 \\
\hline WP $(1,4)$ & 0,9898 \\
\hline $\mathrm{WP}(1,5)$ & 0,9733 \\
\hline WP $(1,6)$ & 0,9569 \\
\hline $\mathrm{WP}(1,7)$ & 0,9898 \\
\hline $\mathrm{WP}(1,8)$ & 0,9733 \\
\hline $\mathrm{WP}(2,1)$ & 0,1626 \\
\hline $\mathrm{WP}(2,3)$ & 0,1516 \\
\hline $\mathrm{WP}(2,4)$ & 0,1626 \\
\hline $\mathrm{WP}(2,5)$ & 0,1626 \\
\hline WP(2,6) & 0,1626 \\
\hline $\mathrm{WP}(2,7)$ & 0,1626 \\
\hline $\mathrm{WP}(2,8)$ & 0,1626 \\
\hline $\mathrm{WP}(3,1)$ & 0,8526 \\
\hline $\mathrm{WP}(3,2)$ & 0,8526 \\
\hline $\mathrm{WP}(3,4)$ & 0,8526 \\
\hline $\mathrm{WP}(3,5)$ & 0,8526 \\
\hline $\mathrm{WP}(3,6)$ & 0,8526 \\
\hline $\mathrm{WP}(3,7)$ & 0,8526 \\
\hline $\mathrm{WP}(3,8)$ & 0,8526 \\
\hline $\mathrm{WP}(4,1)$ & 0,0000 \\
\hline $\mathrm{WP}(4,2)$ & 0,0000 \\
\hline $\mathrm{WP}(4,3)$ & 0,0000 \\
\hline
\end{tabular}

Berikut adalah hasil dari perhitungan bobot yang dibuat menjadi table :

Table 7. WP (Weak Preferential) 


\begin{tabular}{|c|c|}
\hline Alternatif & Nilai \\
\hline $\mathrm{WP}(4,5)$ & 0,0000 \\
\hline $\mathrm{WP}(4,6)$ & 0,0000 \\
\hline $\mathrm{WP}(4,7)$ & 0,0000 \\
\hline $\mathrm{WP}(4,8)$ & 0,0000 \\
\hline $\mathrm{WP}(5,1)$ & 0,8581 \\
\hline $\mathrm{WP}(5,2)$ & 0,8581 \\
\hline $\mathrm{WP}(5,3)$ & 0,8471 \\
\hline WP $(5,4)$ & 0,8581 \\
\hline $\mathrm{WP}(5,6)$ & 0,8581 \\
\hline $\mathrm{WP}(5,7)$ & 0,8581 \\
\hline $\mathrm{WP}(5,8)$ & 0,8581 \\
\hline $\mathrm{WP}(6,1)$ & 0,1739 \\
\hline $\mathrm{WP}(6,2)$ & 0,1575 \\
\hline $\mathrm{WP}(6,3)$ & 0,1630 \\
\hline WP $(6,4)$ & 0,1739 \\
\hline WP(6,5) & 0,1575 \\
\hline $\mathrm{WP}(6,7)$ & 0,1739 \\
\hline $\mathrm{WP}(6,8)$ & 0,1575 \\
\hline WP(7,1) & 0,1359 \\
\hline $\mathrm{WP}(7,2)$ & 0,1359 \\
\hline WP(7,3) & 0,1359 \\
\hline WP $(7,4)$ & 0,1359 \\
\hline WP(7,5) & 0,1359 \\
\hline WP( $(7,6)$ & 0,1359 \\
\hline $\mathrm{WP}(7,8)$ & 0,1359 \\
\hline $\mathrm{WP}(8,1)$ & 0,8632 \\
\hline $\mathrm{WP}(8,2)$ & 0,8632 \\
\hline $\mathrm{WP}(8,3)$ & 0,8522 \\
\hline WP $(8,4)$ & 0,8632 \\
\hline $\mathrm{WP}(8,5)$ & 0,8632 \\
\hline $\mathrm{WP}(8,6)$ & 0,8632 \\
\hline $\mathrm{WP}(8,7)$ & 0,8632 \\
\hline
\end{tabular}

5. Nilai Strict Preferences $J$ atau $\operatorname{SPj}\left(i, i^{\prime}\right)$

Rumus berikut sesuai dengan persamaan 3.6 pada Bab sebelumnya.

$S P_{j}\left(i, i^{\prime}\right)=\left[\max \left(0, d_{j}-L_{j}\right)\right] /\left[d m_{j}-L_{j}\right]$

$\mathrm{C} 1=$ Pendidikan

$S P_{j}(1,2)=[\max (0,(0-1)-0] /[1-0]$

$=\frac{[\max (0)]}{1}=0$

$S P_{j}(1,3)=[\max (0,(0-0)-0] /[1-0]$

$=\frac{[\max (0)]}{1}=0$

$S P_{j}(1,4)=[\max (0,(0-0)-0] /[1-0]$

$=\frac{[\max (0)]}{1}=0$

$S P_{j}(1,5)=[\max (0,(0-0)-0] /[1-0]$

$=\frac{[\max (0)]}{1}=0$

$S P_{j}(1,6)=[\max (0,(0-1)-0] /[1-0]$

$=\frac{[\max (0)]}{1}=0$

$S P_{j}(1,7)=[\max (0,(0-0)-0] /[1-0]$

$=\frac{[\max (0)]}{1}=0$

$S P_{j}(1,8)=[\max (0,(0-0)-0] /[1-0]$

$=\frac{[\max (0)]}{1}=0$

$S P_{j}(2,1)=[\max (0,(1-0)-0] /[1-0]$ 


$$
\begin{aligned}
& =\frac{[\max (1)]}{1}=1 \\
& S P_{j}(2,3)=[\max (0,(1-0)-0] /[1-0]
\end{aligned}
$$$$
=\frac{[\max (1)]}{1}=1
$$

$S P_{j}(2,4)=[\max (0,(1-0)-0] /[1-0]$

$=\frac{[\max (1)]}{1}=1$

$S P_{j}(2,5)=[\max (0,(1-0)-0] /[1-0]$

$=\frac{[\max (1)]}{1}=1$

$S P_{j}(2,6)=[\max (0,(1-1)-0] /[1-0]$

$=\frac{[\max (1)]}{1}=0$

$S P_{j}(2,7)=[\max (0,(1-0)-0] /[1-0]$

$=\frac{[\max (1)]}{1}=1$

$S P_{j}(2,8)=[\max (0,(1-0)-0] /[1-0]$

$=\frac{[\max (1)]}{1}=1$

$S P_{j}(3,1)=[\max (0,(0-0)-0] /[1-0]$

$=\frac{[\max (0)]}{1}=0$

$S P_{j}(3,2)=[\max (0,(0-1)-0] /[1-0]$

$=\frac{[\max (0)]}{1}=0$

$S P_{j}(3,4)=[\max (0,(0-0)-0] /[1-0]$

$=\frac{[\max (0)]}{1}=0$

$S P_{j}(3,5)=[\max (0,(0-0)-0] /[1-0]$

$=\frac{[\max (0)]}{1}=0$

$S P_{j}(3,6)=[\max (0,(0-1)-0] /[1-0]$

$=\frac{[\max (0)]}{1}=0$

$S P_{j}(3,7)=[\max (0,(0-0)-0] /[1-0]$

$=\frac{[\max (0)]}{1}=0$

$S P_{j}(3,8)=[\max (0,(0-0)-0] /[1-0]$

$=\frac{[\max (0)]}{1}=0$

$S P_{j}(4,1)=[\max (0,(0-0)-0] /[1-0]$

$=\frac{[\max (0)]}{1}=0$

$S P_{j}(4,2)=[\max (0,(0-1)-0] /[1-0]$

$=\frac{[\max (0)]}{1}=0$

$S P_{j}(4,3)=[\max (0,(0-0)-0] /[1-0]$

$=\frac{[\max (0)]}{1}=0$

$S P_{j}(4,5)=[\max (0,(0-0)-0] /[1-0]$

$=\frac{[\max (0)]}{1}=0$

$S P_{j}(4,6)=[\max (0,(0-1)-0] /[1-0]$

$=\frac{[\max (0)]}{1}=0$

$S P_{j}(4,7)=[\max (0,(0-0)-0] /[1-0]$ 


$$
\begin{aligned}
& =\frac{[\max (0)]}{1}=0 \\
& S P_{j}(4,8)=[\max (0,(0-0)-0] /[1-0]
\end{aligned}
$$$$
=\frac{[\max (0)]}{1}=0
$$$$
S P_{j}(5,1)=[\max (0,(0-0)-0] /[1-0]
$$$$
=\frac{[\max (0)]}{1}=0
$$

$S P_{j}(5,2)=[\max (0,(0-1)-0] /[1-0]$ $=\frac{[\max (0)]}{1}=0$

$S P_{j}(5,3)=[\max (0,(0-0)-0] /[1-0]$

$=\frac{[\max (0)]}{1}=0$

$S P_{j}(5,4)=[\max (0,(0-0)-0] /[1-0]$

$=\frac{[\max (0)]}{1}=0$

$S P_{j}(5,6)=[\max (0,(0-1)-0] /[1-0]$

$=\frac{[\max (0)]}{1}=0$

$S P_{j}(5,7)=[\max (0,(0-0)-0] /[1-0]$

$=\frac{[\max (0)]}{1}=0$

$S P_{j}(5,8)=[\max (0,(0-0)-0] /[1-0]$

$=\frac{[\max (0)]}{1}=0$

$S P_{j}(6,1)=[\max (0,(1-0)-0] /[1-0]$

$=\frac{[\max (1)]}{1}=1$

$S P_{j}(6,2)=[\max (0,(1-1)-0] /[1-0]$

$=\frac{[\max (0)]}{1}=0$

$S P_{j}(6,3)=[\max (0,(1-0)-0] /[1-0]$

$=\frac{[\max (1)]}{1}=1$

$S P_{j}(6,4)=[\max (0,(1-0)-0] /[1-0]$

$=\frac{[\max (1)]}{1}=1$

$S P_{j}(6,5)=[\max (0,(1-0)-0] /[1-0]$

$=\frac{[\max (1)]}{1}=1$

$S P_{j}(6,7)=[\max (0,(1-0)-0] /[1-0]$

$=\frac{[\max (1)]}{1}=1$

$S P_{j}(6,8)=[\max (0,(1-0)-0] /[1-0]$

$=\frac{[\max (1)]}{1}=1$

$S P_{j}(7,1)=[\max (0,(0-0)-0] /[1-0]$

$=\frac{[\max (0)]}{1}=0$

$S P_{j}(7,2)=[\max (0,(0-1)-0] /[1-0]$

$=\frac{[\max (0)]}{1}=0$

$S P_{j}(7,3)=[\max (0,(0-0)-0] /[1-0]$

$=\frac{[\max (0)]}{1}=0$

$S P_{j}(7,4)=[\max (0,(0-0)-0] /[1-0]$ 


$$
\begin{aligned}
& =\frac{[\max (0)]}{1}=0 \\
& S P_{j}(7,5)=[\max (0,(0-0)-0] /[1-0] \\
& =\frac{[\max (0)]}{1}=0 \\
& S P_{j}(7,6)=[\max (0,(0-1)-0] /[1-0] \\
& =\frac{[\max (0)]}{1}=0 \\
& S P_{j}(7,8)=[\max (0,(0-0)-0] /[1-0] \\
& =\frac{[\max (0)]}{1}=0
\end{aligned}
$$

C2 = Bidang Keahlian

$S P_{j}(1,2)=[\max (0,(1-0)-0] /[1-0]$

$=\frac{[\max (1)]}{1}=1$

$S P_{j}(1,3)=[\max (0,(1-1)-0] /[1-0]$

$=\frac{[\max (0)]}{1}=0$

$S P_{j}(1,4)=[\max (0,(1-0)-0] /[1-0]$

$=\frac{[\max (1)]}{1}=1$

$S P_{j}(1,5)=[\max (0,(1-1)-0] /[1-0]$

$=\frac{[\max (0)]}{1}=0$

$S P_{j}(1,6)=[\max (0,(1-0)-0] /[1-0]$

$=\frac{[\max (1)]}{1}=1$

$S P_{j}(1,7)=[\max (0,(1-0)-0] /[1-0]$

$=\frac{[\max (1)]}{1}=1$

$S P_{j}(1,8)=[\max (0,(1-1)-0] /[1-0]$

$=\frac{[\max (0)]}{1}=0$

$S P_{j}(2,1)=[\max (0,(0-1)-0] /[1-0]$

$=\frac{[\max (0)]}{1}=0$

$S P_{j}(2,3)=[\max (0,(0-1)-0] /[1-0]$

$=\frac{[\max (0)]}{1}=0$

$S P_{j}(2,4)=[\max (0,(0-0)-0] /[1-0]$

$=\frac{[\max (0)]}{1}=0$

$S P_{j}(2,5)=[\max (0,(0-1)-0] /[1-0]$

$=\frac{[\max (0)]}{1}=0$

$S P_{j}(2,6)=[\max (0,(0-0)-0] /[1-0]$

$=\frac{[\max (0)]}{1}=0$

$S P_{j}(2,7)=[\max (0,(0-0)-0] /[1-0]$

$=\frac{[\max (0)]}{1}=0$

$S P_{j}(2,8)=[\max (0,(0-1)-0] /[1-0]$

$=\frac{[\max (0)]}{1}=0$

$S P_{j}(3,1)=[\max (0,(1-1)-0] /[1-0]$

$=\frac{[\max (0)]}{1}=0$

$S P_{j}(3,2)=[\max (0,(1-0)-0] /[1-0]$ 


$$
\begin{aligned}
& =\frac{[\max (1)]}{1}=0 \\
& S P_{j}(3,4)=[\max (0,(1-0)-0] /[1-0]
\end{aligned}
$$$$
=\frac{[\max (1)]}{1}=1
$$$$
S P_{j}(3,5)=[\max (0,(1-1)-0] /[1-0]
$$$$
=\frac{[\max (0)]}{1}=0
$$

$S P_{j}(3,6)=[\max (0,(1-0)-0] /[1-0]$ $=\frac{[\max (1)]}{1}=0$

$S P_{j}(3,7)=[\max (0,(1-0)-0] /[1-0]$ $=\frac{[\max (1)]}{1}=1$

$S P_{j}(3,8)=[\max (0,(1-1)-0] /[1-0]$ $=\frac{[\max (0)]}{1}=0$

$S P_{j}(4,1)=[\max (0,(0-1)-0] /[1-0]$ $=\frac{[\max (0)]}{1}=0$

$S P_{j}(4,2)=[\max (0,(0-0)-0] /[1-0]$ $=\frac{[\max (0)]}{1}=0$

$S P_{j}(4,3)=[\max (0,(0-1)-0] /[1-0]$ $=\frac{[\max (0)]}{1}=0$

$S P_{j}(4,5)=[\max (0,(0-1)-0] /[1-0]$ $=\frac{[\max (0)]}{1}=0$

$S P_{j}(4,6)=[\max (0,(0-0)-0] /[1-0]$ $=\frac{[\max (0)]}{1}=0$

$S P_{j}(4,7)=[\max (0,(0-0)-0] /[1-0]$ $=\frac{[\max (0)]}{1}=0$

$S P_{j}(4,8)=[\max (0,(0-1)-0] /[1-0]$ $=\frac{[\max (0)]}{1}=0$

$S P_{j}(5,1)=[\max (0,(1-1)-0] /[1-0]$ $=\frac{[\max (0)]}{1}=0$

$S P_{j}(5,2)=[\max (0,(1-0)-0] /[1-0]$ $=\frac{[\max (1)]}{1}=1$

$S P_{j}(5,3)=[\max (0,(1-1)-0] /[1-0]$ $=\frac{[\max (0)]}{1}=0$

$S P_{j}(5,4)=[\max (0,(1-0)-0] /[1-0]$ $=\frac{[\max (1)]}{1}=1$

$S P_{j}(5,6)=[\max (0,(1-0)-0] /[1-0]$ $=\frac{[\max (1)]}{1}=1$

$S P_{j}(5,7)=[\max (0,(1-0)-0] /[1-0]$

$=\frac{[\max (0)]}{1}=0$

$S P_{j}(5,8)=[\max (0,(1-1)-0] /[1-0]$ 


$$
\begin{aligned}
& =\frac{[\max (0)]}{1}=0 \\
& S P_{j}(6,1)=[\max (0,(0-1)-0] /[1-0]
\end{aligned}
$$$$
=\frac{[\max (0)]}{1}=0
$$$$
S P_{j}(6,2)=[\max (0,(0-0)-0] /[1-0]
$$$$
=\frac{[\max (0)]}{1}=0
$$

$S P_{j}(6,3)=[\max (0,(0-1)-0] /[1-0]$ $=\frac{[\max (0)]}{1}=0$

$S P_{j}(6,4)=[\max (0,(0-0)-0] /[1-0]$ $=\frac{[\max (0)]}{1}=0$

$S P_{j}(6,5)=[\max (0,(0-1)-0] /[1-0]$ $=\frac{[\max (0)]}{1}=0$

$S P_{j}(6,7)=[\max (0,(0-0)-0] /[1-0]$ $=\frac{[\max (0)]}{1}=0$

$S P_{j}(6,8)=[\max (0,(0-1)-0] /[1-0]$ $=\frac{[\max (0)]}{1}=0$

$S P_{j}(7,1)=[\max (0,(0-1)-0] /[1-0]$ $=\frac{[\max (0)]}{1}=0$

$S P_{j}(7,2)=[\max (0,(0-0)-0] /[1-0]$ $=\frac{[\max (0)]}{1}=0$

$S P_{j}(7,3)=[\max (0,(0-1)-0] /[1-0]$ $=\frac{[\max (0)]}{1}=0$

$S P_{j}(7,4)=[\max (0,(0-0)-0] /[1-0]$ $=\frac{[\max (0)]}{1}=0$

$S P_{j}(7,5)=[\max (0,(0-1)-0] /[1-0]$ $=\frac{[\max (0)]}{1}=0$

$S P_{j}(7,6)=[\max (0,(0-0)-0] /[1-0]$ $=\frac{[\max (0)]}{1}=0$

$S P_{j}(7,8)=[\max (0,(0-1)-0] /[1-0]$ $=\frac{[\max (0)]}{1}=0$

$S P_{j}(8,1)=[\max (0,(1-1)-0] /[1-0]$ $=\frac{[\max (0)]}{1}=0$

$S P_{j}(8,2)=[\max (0,(1-0)-0] /[1-0]$ $=\frac{[\max (1)]}{1}=1$

$S P_{j}(8,3)=[\max (0,(1-1)-0] /[1-0]$ $=\frac{[\max (0)]}{1}=0$

$S P_{j}(8,4)=[\max (0,(1-0)-0] /[1-0]$

$=\frac{[\max (1)]}{1}=1$

$S P_{j}(8,5)=[\max (0,(1-1)-0] /[1-0]$ 


\section{Journal of Computer System and Informatics (JoSYC)}

Volume 3, No. 1, November 2021, Page 26-56

ISSN 2714-8912 (media online)

ISSN 2714-7150 (media cetak)

DOI 10.47065/josyc.v3i1.821

$$
\begin{aligned}
& =\frac{[\max (0)]}{1}=0 \\
& S P_{j}(8,6)=[\max (0,(1-0)-0] /[1-0] \\
& =\frac{[\max (1)]}{1}=1 \\
& S P_{j}(8,7)=[\max (0,(1-1)-0] /[1-0] \\
& =\frac{[\max (0)]}{1}=0
\end{aligned}
$$

Nilai Strict Preferences atau $S P\left(i, i^{\prime}\right)$

$$
\begin{aligned}
S P(i, i) & =\left[\sum_{j=1}^{n} W_{j} x S P_{j}(i, i)\right] / \sum_{j=1}^{n} W_{j} \\
& =\frac{\left[\left(W_{1} x S P_{1}(1,2)\right)+\left(W_{2} x S P_{2}(1,2)\right)+\left(W_{3} x S P_{3}(1,2)\right)+\left(W_{4} x S P_{4}(1,2)\right)+\left(W_{5} x S P_{5}(1,2)\right]\right.}{1} \\
& =\frac{[(0,0051 * 0)+(0,7057 * 1)+(0,1482 * 0,8889)+(0,1359 * 0)+(0,0051 * 0)]}{1} \\
S P(1,2) & =0,8374 \\
& =\frac{\left[\left(W_{1} x S P_{1}(1,2)\right)+\left(W_{2} x S P_{2}(1,2)\right)+\left(W_{3} x S P_{3}(1,2)\right)+\left(W_{4} x S P_{4}(1,2)\right)+\left(W_{5} x S P_{5}(1,2)\right]\right.}{1} \\
& =\frac{[(0,0051 * 0)+(0,7057 * 0)+(0,1482 * 0,9259)+(0,1359 * 0)+(0,0051 * 0)]}{1}
\end{aligned}
$$$$
\begin{gathered}
=\frac{\left[\left(W_{1} x S P_{1}(1,4)\right)+\left(W_{2} x S P_{2}(1,4)\right)+\left(W_{3} x S P_{3}(1,4)\right)+\left(W_{4} x S P_{4}(1,4)\right)+\left(W_{5} x S P_{5}(1,4)\right]\right.}{1} \\
=\frac{[(0,0051 * 0)+(0,7057 * 1)+(0,1482 * 1)+(0,1359 * 1)+(0,0051 * 0)]}{1}
\end{gathered}
$$$$
S P(1,4)=0,9898
$$$$
\begin{aligned}
& =\frac{\left[\left(W_{1} x S P_{1}(1,5)\right)+\left(W_{2} x S P_{2}(1,5)\right)+\left(W_{3} x S P_{3}(1,5)\right)+\left(W_{4} x S P_{4}(1,5)\right)+\left(W_{5} x S P_{5}(1,5)\right]\right.}{1} \\
& =\frac{[(0,0051 * 0)+(0,7057 * 0)+(0,1482 * 0,8889)+(0,1359 * 0)+(0,0051 * 0)]}{1}
\end{aligned}
$$$$
S P(1,5)=0,1317
$$$$
\begin{gathered}
=\frac{\left[\left(W_{1} x S P_{1}(1,6)\right)+\left(W_{2} x S P_{2}(1,6)\right)+\left(W_{3} x S P_{3}(1,6)\right)+\left(W_{4} x S P_{4}(1,6)\right)+\left(W_{5} x S P_{5}(1,6)\right]\right.}{1} \\
=\frac{[(0,0051 * 0)+(0,7057 * 1)+(0,1482 * 0,7778)+(0,1359 * 0)+(0,0051 * 0)]}{1}
\end{gathered}
$$$$
S P(1,6)=0,8210
$$$$
\begin{gathered}
=\frac{\left[\left(W_{1} x S P_{1}(1,7)\right)+\left(W_{2} x S P_{2}(1,7)\right)+\left(W_{3} x S P_{3}(1,7)\right)+\left(W_{4} x S P_{4}(1,7)\right)+\left(W_{5} x S P_{5}(1,7)\right]\right.}{1} \\
=\frac{[(0,0051 * 0)+(0,7057 * 1)+(0,1482 * 1)+(0,1359 * 0)+(0,0051 * 0)]}{1}
\end{gathered}
$$

$$
\begin{aligned}
S P(1,7) & =0,8539 \\
= & \frac{\left[\left(W_{1} x S P_{1}(1,7)\right)+\left(W_{2} x S P_{2}(1,7)\right)+\left(W_{3} x S P_{3}(1,7)\right)+\left(W_{4} x S P_{4}(1,7)\right)+\left(W_{5} x S P_{5}(1,7)\right]\right.}{1} \\
& =\frac{[(0,0051 * 0)+(0,7057 * 0)+(0,1482 * 0,8889)+(0,1359 * 0)+(0,0051 * 0)]}{1}
\end{aligned}
$$

$S P(1,8)=0,1317$

$$
\begin{gathered}
=\frac{\left[\left(W_{1} \times S P_{1}(2,1)\right)+\left(W_{2} x S P_{2}(2,1)\right)+\left(W_{3} x S P_{3}(2,1)\right)+\left(W_{4} x S P_{4}(2,1)\right)+\left(W_{5} \times S P_{5}(2,1)\right]\right.}{1} \\
=\frac{[(0,0051 * 1)+(0,7057 * 0)+(0,1482 * 0)+(0,1359 * 0)+(0,0051 * 1)]}{1}
\end{gathered}
$$

$S P(2,1)=0,0102$

$$
\begin{gathered}
=\frac{\left[\left(W_{1} x S P_{1}(2,3)\right)+\left(W_{2} x S P_{2}(2,3)\right)+\left(W_{3} x S P_{3}(2,3)\right)+\left(W_{4} x S P_{4}(2,3)\right)+\left(W_{5} x S P_{5}(2,3)\right]\right.}{1} \\
=\frac{[(0,0051 * 1)+(0,7057 * 0)+(0,1482 * 0,0370)+(0,1359 * 0)+(0,0051 * 1)]}{1}
\end{gathered}
$$

$S P(2,3)=0,0157$

$$
=\frac{\left[\left(W_{1} x S P_{1}(2,4)\right)+\left(W_{2} x S P_{2}(2,4)\right)+\left(W_{3} x S P_{3}(2,4)\right)+\left(W_{4} x S P_{4}(2,4)\right)+\left(W_{5} x S P_{5}(2,4)\right]\right.}{1}
$$


$S P(2,4)=0,1626$

$$
=\frac{[(0,0051 * 1)+(0,7057 * 0)+(0,1482 * 0,1111)+(0,1359 * 1)+(0,0051 * 1)]}{1}
$$

$$
\begin{gathered}
=\frac{\left[\left(W_{1} x S P_{1}(2,5)\right)+\left(W_{2} x S P_{2}(2,5)\right)+\left(W_{3} x S P_{3}(2,5)\right)+\left(W_{4} x S P_{4}(2,5)\right)+\left(W_{5} x S P_{5}(2,5)\right]\right.}{1} \\
=\frac{[(0,0051 * 1)+(0,7057 * 0)+(0,1482 * 0)+(0,1359 * 0)+(0,0051 * 1)]}{1}
\end{gathered}
$$

$S P(2,5)=0,0102$

$$
\begin{gathered}
=\frac{\left[\left(W_{1} x S P_{1}(2,6)\right)+\left(W_{2} x S P_{2}(2,6)\right)+\left(W_{3} x S P_{3}(2,6)\right)+\left(W_{4} x S P_{4}(2,6)\right)+\left(W_{5} x S P_{5}(2,6)\right]\right.}{1} \\
=\frac{[(0,0051 * 0)+(0,7057 * 0)+(0,1482 * 0)+(0,1359 * 0)+(0,0051 * 1)]}{1}
\end{gathered}
$$

$S P(2,6)=0,0051$

$$
\begin{gathered}
=\frac{\left[\left(W_{1} x S P_{1}(2,7)\right)+\left(W_{2} x S P_{2}(2,7)\right)+\left(W_{3} x S P_{3}(2,7)\right)+\left(W_{4} x S P_{4}(2,7)\right)+\left(W_{5} x S P_{5}(2,7)\right]\right.}{1} \\
=\frac{[(0,0051 * 1)+(0,7057 * 0)+(0,1482 * 0,1111)+(0,1359 * 0)+(0,0051 * 1)]}{1}
\end{gathered}
$$

$S P(2,7)=0,0267$

$$
\begin{gathered}
=\frac{\left[\left(W_{1} x S P_{1}(2,7)\right)+\left(W_{2} x S P_{2}(2,7)\right)+\left(W_{3} x S P_{3}(2,7)\right)+\left(W_{4} x S P_{4}(2,7)\right)+\left(W_{5} x S P_{5}(2,7)\right]\right.}{1} \\
=\frac{[(0,0051 * 1)+(0,7057 * 0)+(0,1482 * 0)+(0,1359 * 0)+(0,0051 * 0)]}{1}
\end{gathered}
$$

$S P(2,8)=0,0051$

$$
\begin{gathered}
=\frac{\left[\left(W_{1} x S P_{1}(3,1)\right)+\left(W_{2} x S P_{2}(3,1)\right)+\left(W_{3} x S P_{3}(3,1)\right)+\left(W_{4} x S P_{4}(3,1)\right)+\left(W_{5} x S P_{5}(3,1)\right]\right.}{1} \\
=\frac{[(0,0051 * 0)+(0,7057 * 0)+(0,1482 * 0)+(0,1359 * 0)+(0,0051 * 0)]}{1}
\end{gathered}
$$

Hasil dari setiap perhitungan di atas dibuat menjadi tabel sebagai berikut:

Tabel 8. SP (Strict Preferences)

\begin{tabular}{cc}
\hline Alternatif & Nilai \\
\hline $\mathrm{SP}(1,2)$ & 0,8374 \\
$\mathrm{SP}(1,3)$ & 0,1372 \\
$\mathrm{SP}(1,4)$ & 0,9898 \\
$\mathrm{SP}(1,5)$ & 0,1317 \\
$\mathrm{SP}(1,6)$ & 0,8210 \\
$\mathrm{SP}(1,7)$ & 0,8539 \\
$\mathrm{SP}(1,8)$ & 0,1317 \\
$\mathrm{SP}(2,1)$ & 0,0102 \\
$\mathrm{SP}(2,3)$ & 0,0157 \\
$\mathrm{SP}(2,4)$ & 0,1626 \\
$\mathrm{SP}(2,5)$ & 0,0102 \\
$\mathrm{SP}(2,6)$ & 0,0051 \\
$\mathrm{SP}(2,7)$ & 0,0267 \\
$\mathrm{SP}(2,8)$ & 0,0051 \\
$\mathrm{SP}(3,1)$ & 0,0000 \\
$\mathrm{SP}(3,2)$ & 0,7057 \\
$\mathrm{SP}(3,4)$ & 0,8526 \\
$\mathrm{SP}(3,5)$ & 0,0000 \\
$\mathrm{SP}(3,6)$ & 0,7057 \\
$\mathrm{SP}(3,7)$ & 0,7167 \\
$\mathrm{SP}(3,8)$ & 0,0000 \\
$\mathrm{SP}(4,1)$ & 0,0000 \\
$\mathrm{SP}(4,2)$ & 0,0000 \\
$\mathrm{SP}(4,3)$ & 0,0000 \\
$\mathrm{SP}(4,5)$ & 0,0000 \\
$\mathrm{SP}(4,6)$ & 0,0000 \\
$\mathrm{SP}(4,7)$ & 0,0000 \\
$\mathrm{SP}(4,8)$ & 0,0000 \\
$\mathrm{SP}(5,1)$ & 0,0000 \\
\hline
\end{tabular}


Journal of Computer System and Informatics (JoSYC)

Volume 3, No. 1, November 2021, Page 26-56

ISSN 2714-8912 (media online)

ISSN 2714-7150 (media cetak)

DOI 10.47065/josyc.v3i1.821

\begin{tabular}{|c|c|}
\hline Alternatif & Nilai \\
\hline $\mathrm{SP}(5,2)$ & 0,7057 \\
\hline $\operatorname{SP}(5,3)$ & 0,0055 \\
\hline $\mathrm{SP}(5,4)$ & 0,8581 \\
\hline $\mathrm{SP}(5,6)$ & 0,7057 \\
\hline $\mathrm{SP}(5,7)$ & 0,7222 \\
\hline $\mathrm{SP}(5,8)$ & 0,0000 \\
\hline $\mathrm{SP}(6,1)$ & 0,0051 \\
\hline $\mathrm{SP}(6,2)$ & 0,0165 \\
\hline $\mathrm{SP}(6,3)$ & 0,0271 \\
\hline $\mathrm{SP}(6,4)$ & 0,1739 \\
\hline $\mathrm{SP}(6,5)$ & 0,0216 \\
\hline $\mathrm{SP}(6,7)$ & 0,0380 \\
\hline $\mathrm{SP}(6,8)$ & 0,0216 \\
\hline $\operatorname{SP}(7,1)$ & 0,0000 \\
\hline $\mathrm{SP}(7,2)$ & 0,0000 \\
\hline $\operatorname{SP}(7,3)$ & 0,0000 \\
\hline $\mathrm{SP}(7,4)$ & 0,1359 \\
\hline $\mathrm{SP}(7,5)$ & 0,0000 \\
\hline $\operatorname{SP}(7,6)$ & 0,0000 \\
\hline $\operatorname{SP}(7,8)$ & 0,0000 \\
\hline $\mathrm{SP}(8,1)$ & 0,0051 \\
\hline $\mathrm{SP}(8,2)$ & 0,7057 \\
\hline $\mathrm{SP}(8,3)$ & 0,0106 \\
\hline $\mathrm{SP}(8,4)$ & 0,8632 \\
\hline $\mathrm{SP}(8,5)$ & 0,0051 \\
\hline $\mathrm{SP}(8,6)$ & 0,7108 \\
\hline $\operatorname{SP}(8,7)$ & 0,7273 \\
\hline
\end{tabular}

6. Menghitung nilai $T P\left(i, i^{\prime}\right)$

Nilai total preference merupakan penjumlahan dari hasil nilai weak preferential dan hasil nilai stric preference yang nantinya hasil dari pemjumlahan keduanya akan dimasukan menjadi nilai keseluruhan preferensi.

$\mathrm{TP}\left(\mathrm{i}, \mathrm{i}^{\prime}\right)=\operatorname{Min}\left[1, \mathrm{WP}\left(\mathrm{i}, \mathrm{i}^{\prime}\right)+\mathrm{SP}\left(\mathrm{i}, \mathrm{i}^{\prime}\right)\right]$

Tabel 9. Total Preference dari WP Dan SP

\begin{tabular}{|c|c|}
\hline Alternatif & Perhitungan \\
\hline $\mathrm{TP}(1,2)$ & $\operatorname{Min}[1,0,9158+0,7209]=1$ \\
\hline $\mathrm{TP}(1,3)$ & $\operatorname{Min}[1,0,9332+0,4332]=1$ \\
\hline $\mathrm{TP}(1,4)$ & $\operatorname{Min}[1,0,9678+0,9678]=1$ \\
\hline $\mathrm{TP}(1,5)$ & $\operatorname{Min}[1,0,9158+0,4159]=1$ \\
\hline $\mathrm{TP}(1,6)$ & $\operatorname{Min}[1,0,8638+0,6689]=1$ \\
\hline $\mathrm{TP}(1,7)$ & $\operatorname{Min}[1,0,9678+0,7729]=1$ \\
\hline $\mathrm{TP}(1,8)$ & $\operatorname{Min}[1,0,9158+0,4159]=1$ \\
\hline $\mathrm{TP}(2,1)$ & $\operatorname{Min}[1,0,2791+0,0322]=0,3113$ \\
\hline $\mathrm{TP}(2,3)$ & $\operatorname{Min}[1,0,2445+0,0495]=0,2940$ \\
\hline $\mathrm{TP}(2,4)$ & $\operatorname{Min}[1,0,2791+0,2791]=0,5583$ \\
\hline $\mathrm{TP}(2,5)$ & $\operatorname{Min}[1,0,2791+0,0322]=0,3113$ \\
\hline $\mathrm{TP}(2,6)$ & $\operatorname{Min}[1,0,2791+0,0051]=0,2952$ \\
\hline $\mathrm{TP}(2,6)$ & $\operatorname{Min}[1,0,2791+0,0842]=0,3633$ \\
\hline $\mathrm{TP}(2,8)$ & $\operatorname{Min}[1,0,2791+0,0051]=0,2952$ \\
\hline $\mathrm{TP}(3,1)$ & $\operatorname{Min}[1,0,5346+0]=0,5346$ \\
\hline $\mathrm{TP}(3,2)$ & $\operatorname{Min}[1,0,5346+0,7057]=0,8396$ \\
\hline $\mathrm{TP}(3,4)$ & $\operatorname{Min}[1,0,5346+0,5346]=1$ \\
\hline $\mathrm{TP}(3,5)$ & $\operatorname{Min}[1,0,5346+0]=0,5346$ \\
\hline $\mathrm{TP}(3,6)$ & $\operatorname{Min}[1,0,5346+0,7057]=0,8396$ \\
\hline $\mathrm{TP}(3,7)$ & $\operatorname{Min}[1,0,5346+0,3396]=0,8742$ \\
\hline $\mathrm{TP}(3,8)$ & $\operatorname{Min}[1,0,5346+0]=0,5346$ \\
\hline $\mathrm{TP}(4,1)$ & $\operatorname{Min}[1,0+0]=0$ \\
\hline $\mathrm{TP}(4,2)$ & $\operatorname{Min}[1,0+0]=0$ \\
\hline $\mathrm{TP}(4,3)$ & $\operatorname{Min}[1,0+0]=0$ \\
\hline $\mathrm{TP}(4,5)$ & $\operatorname{Min}[1,0+0]=0$ \\
\hline
\end{tabular}




\begin{tabular}{|c|c|}
\hline Alternatif & Perhitungan \\
\hline $\mathrm{TP}(4,6)$ & $\operatorname{Min}[1,0+0]=0$ \\
\hline $\mathrm{TP}(4,7)$ & $\operatorname{Min}[1,0+0]=0$ \\
\hline $\mathrm{TP}(4,8)$ & $\operatorname{Min}[1,0+0]=0$ \\
\hline $\mathrm{TP}(5,1)$ & $\operatorname{Min}[1,0,5519+0]=0,5519$ \\
\hline $\mathrm{TP}(5,2)$ & $\operatorname{Min}[1,0,5519+0,7057]=0,8569$ \\
\hline $\mathrm{TP}(5,3)$ & $\operatorname{Min}[1,0,5173+0,0173]=0,5346$ \\
\hline $\mathrm{TP}(5,4)$ & $\operatorname{Min}[1,0,5519+0,5519]=1$ \\
\hline $\mathrm{TP}(5,6)$ & $\operatorname{Min}[1,0,5519+0,7057]=0,8569$ \\
\hline $\mathrm{TP}(5,7)$ & $\operatorname{Min}[1,0,5519+0,3570]=0,9089$ \\
\hline $\mathrm{TP}(5,8)$ & $\operatorname{Min}[1,0,5519+0]=0,5519$ \\
\hline $\mathrm{TP}(6,1)$ & $\operatorname{Min}[1,0,3150+0,0051]=0,3311$ \\
\hline $\mathrm{TP}(6,2)$ & $\operatorname{Min}[1,0,2630+0,0520]=0,3150$ \\
\hline $\mathrm{TP}(6,3)$ & $\operatorname{Min}[1,0,2804+0,0854]=0,3658$ \\
\hline $\mathrm{TP}(6,4)$ & $\operatorname{Min}[1,0,3150+0,3150]=0,6301$ \\
\hline $\mathrm{TP}(6,5)$ & $\operatorname{Min}[1,0,2630+0,0681]=0,3311$ \\
\hline $\mathrm{TP}(6,7)$ & $\operatorname{Min}[1,0,3150+0,1201]=0,4351$ \\
\hline $\mathrm{TP}(6,8)$ & $\operatorname{Min}[1,0,2630+0,0681]=0,3311$ \\
\hline $\mathrm{TP}(7,1)$ & $\operatorname{Min}[1,0,1359+0]=0,1359$ \\
\hline $\mathrm{TP}(7,2)$ & $\operatorname{Min}[1,0,1359+0]=0,1359$ \\
\hline $\mathrm{TP}(7,3)$ & $\operatorname{Min}[1,0,1359+0]=0,1359$ \\
\hline $\mathrm{TP}(7,4)$ & $\operatorname{Min}[1,0,1359+0,1359]=0,3899$ \\
\hline $\mathrm{TP}(7,5)$ & $\operatorname{Min}[1,0,1359+0]=0,1359$ \\
\hline $\mathrm{TP}(7,6)$ & $\operatorname{Min}[1,0,1359+0]=0,1359$ \\
\hline $\mathrm{TP}(7,8)$ & $\operatorname{Min}[1,0,1359+0]=0,1359$ \\
\hline $\mathrm{TP}(8,1)$ & $\operatorname{Min}[1,0,5680+0,0051]=0,5841$ \\
\hline $\mathrm{TP}(8,2)$ & $\operatorname{Min}[1,0,5680+0,7057]=0,8730$ \\
\hline $\mathrm{TP}(8,3)$ & $\operatorname{Min}[1,0,5333+0,0334]=0,5668$ \\
\hline $\mathrm{TP}(8,4)$ & $\operatorname{Min}[1,0,5680+0,5680]=1$ \\
\hline $\mathrm{TP}(8,5)$ & $\operatorname{Min}[1,0,5680+0,0051]=0,5841$ \\
\hline $\mathrm{TP}(8,6)$ & $\operatorname{Min}[1,0,5680+0,3211]=0,8891$ \\
\hline $\mathrm{TP}(8,7)$ & $\operatorname{Min}[1,0,5680+0,3730]=0,9411$ \\
\hline
\end{tabular}

Berikut adalah hasil perhitungan dari setiap alternatif dalam bentuk tabel.

Tabel 10. Niali $W P\left(i, i^{\prime}\right), S P\left(i, i^{\prime}\right)$ Dan $T P\left(i, i^{\prime}\right)$

\begin{tabular}{cccc}
\hline Alternatif & $\boldsymbol{W P}\left(\boldsymbol{i}, \boldsymbol{i}^{\prime}\right)$ & $\boldsymbol{S P}\left(\boldsymbol{i}, \boldsymbol{i}^{\prime}\right)$ & $\boldsymbol{T P}\left(\boldsymbol{i}, \boldsymbol{i}^{\prime}\right)$ \\
\hline$(1,2)$ & 0,9733 & 0,8374 & 1,0000 \\
$(1,3)$ & 0,9788 & 0,1372 & 1,0000 \\
$(1,4)$ & 0,9898 & 0,9898 & 1,0000 \\
$(1,5)$ & 0,9733 & 0,1317 & 1,0000 \\
$(1,6)$ & 0,9569 & 0,8210 & 1,0000 \\
$(1,7)$ & 0,9898 & 0,8539 & 1,0000 \\
$(1,8)$ & 0,9733 & 0,1317 & 1,0000 \\
$(2,1)$ & 0,1626 & 0,0102 & 0,1728 \\
$(2,3)$ & 0,1516 & 0,0157 & 0,1673 \\
$(2,4)$ & 0,1626 & 0,1626 & 0,3251 \\
$(2,5)$ & 0,1626 & 0,0102 & 0,1728 \\
$(2,6)$ & 0,1626 & 0,0051 & 0,1677 \\
$(2,7)$ & 0,1626 & 0,0267 & 0,1892 \\
$(2,8)$ & 0,1626 & 0,0051 & 0,1677 \\
$(3,1)$ & 0,8526 & 0,0000 & 0,8526 \\
$(3,2)$ & 0,8526 & 0,7057 & 1,0000 \\
$(3,4)$ & 0,8526 & 0,8526 & 1,0000 \\
$(3,5)$ & 0,8526 & 0,0000 & 0,8526 \\
$(3,6)$ & 0,8526 & 0,7057 & 1,0000 \\
$(3,7)$ & 0,8526 & 0,7167 & 1,0000 \\
$(3,8)$ & 0,8526 & 0,0000 & 0,8526 \\
$(4,1)$ & 0,0000 & 0,0000 & 0,0000 \\
$(4,2)$ & 0,0000 & 0,0000 & 0,0000 \\
$(4,3)$ & 0,0000 & 0,0000 & 0,0000 \\
\hline
\end{tabular}


Journal of Computer System and Informatics (JoSYC)

Volume 3, No. 1, November 2021, Page 26-56

ISSN 2714-8912 (media online)

ISSN 2714-7150 (media cetak)

DOI 10.47065/josyc.v3i1.821

\begin{tabular}{cccc}
\hline Alternatif & $\boldsymbol{W P}\left(\boldsymbol{i}, \boldsymbol{i}^{\prime}\right)$ & $\boldsymbol{S P}\left(\boldsymbol{i}, \boldsymbol{i}^{\prime}\right)$ & $\boldsymbol{T P}\left(\boldsymbol{i}, \boldsymbol{i}^{\prime}\right)$ \\
\hline$(4,5)$ & 0,0000 & 0,0000 & 0,0000 \\
$(4,6)$ & 0,0000 & 0,0000 & 0,0000 \\
$(4,7)$ & 0,0000 & 0,0000 & 0,0000 \\
$(4,8)$ & 0,0000 & 0,0000 & 0,0000 \\
$(5,1)$ & 0,8581 & 0,0000 & 0,8581 \\
$(5,2)$ & 0,8581 & 0,7057 & 1,0000 \\
$(5,3)$ & 0,8471 & 0,0055 & 0,8526 \\
$(5,4)$ & 0,8581 & 0,8581 & 1,0000 \\
$(5,6)$ & 0,8581 & 0,7057 & 1,0000 \\
$(5,7)$ & 0,8581 & 0,7222 & 1,0000 \\
$(5,8)$ & 0,8581 & 0,0000 & 0,8581 \\
$(6,1)$ & 0,1739 & 0,0051 & 0,1790 \\
$(6,2)$ & 0,1575 & 0,0165 & 0,1739 \\
$(6,3)$ & 0,1630 & 0,0271 & 0,1900 \\
$(6,4)$ & 0,1739 & 0,1739 & 0,3479 \\
$(6,5)$ & 0,1575 & 0,0216 & 0,1790 \\
$(6,7)$ & 0,1739 & 0,0380 & 0,2120 \\
$(6,8)$ & 0,1575 & 0,0216 & 0,1790 \\
$(7,1)$ & 0,1359 & 0,0000 & 0,1359 \\
$(7,2)$ & 0,1359 & 0,0000 & 0,1359 \\
$(7,3)$ & 0,1359 & 0,0000 & 0,1359 \\
$(7,4)$ & 0,1359 & 0,1359 & 0,2718 \\
$(7,5)$ & 0,1359 & 0,0000 & 0,1359 \\
$(7,6)$ & 0,1359 & 0,0000 & 0,1359 \\
$(7,8)$ & 0,1359 & 0,0000 & 0,1359 \\
$(8,1)$ & 0,8632 & 0,0051 & 0,8683 \\
$(8,2)$ & 0,8632 & 0,7057 & 1,0000 \\
$(8,3)$ & 0,8522 & 0,0106 & 0,8628 \\
$(8,4)$ & 0,8632 & 0,8632 & 1,0000 \\
$(8,5)$ & 0,8632 & 0,0051 & 0,8683 \\
$(8,6)$ & 0,8632 & 0,7108 & 1,0000 \\
$(8,7)$ & 0,8632 & 0,7273 & 1,0000 \\
\hline & & & \\
$(8)$ & & \\
$(8)$ & &
\end{tabular}

Nilai pada tabel dibawah ini merupakan nilai hasil dari total preferensi dan diisi sesuai penyandingan nilai baris dan kolom alternatif dan kriteria.

Tabel 11. Dari keseluruhan preferensi

\begin{tabular}{cccccccccc}
\hline Alternatif & $\mathbf{A 1}$ & $\mathbf{A 2}$ & $\mathbf{A 3}$ & $\mathbf{A 4}$ & $\mathbf{A 5}$ & $\mathbf{A 6}$ & $\mathbf{A 7}$ & $\mathbf{A 8}$ & Total \\
\hline $\mathbf{A 1}$ & - & 1 & 1 & 1 & 1 & 1 & 1 & 1 & 7 \\
$\mathbf{A 2}$ & 0,1728 & - & 0,1673 & 0,3251 & 0,1728 & 0,1677 & 0,1892 & 0,1677 & 1,3625 \\
$\mathbf{A 3}$ & 0,8526 & 1,0000 & - & 1 & 0,8526 & 1,0000 & 1,0000 & 0,8526 & 6,5577 \\
A4 & 0 & 0 & 0 & - & 0 & 0 & 0 & 0 & 0 \\
A5 & 0,8581 & 1,0000 & 0,8526 & 1 & - & 1,0000 & 1,0000 & 0,8581 & 6,5687 \\
A6 & 0,1790 & 0,1739 & 0,1900 & 0,3479 & 0,1790 & - & 0,2120 & 0,1790 & 1,4609 \\
A7 & 0,1359 & 0,1359 & 0,1359 & 0,2718 & 0,1359 & 0,1359 & - & 0,1359 & 1,0872 \\
A8 & 0,8683 & 1,0000 & 0,8628 & 1 & 0,8683 & 1,0000 & 1,0000 & - & 6,5993 \\
Total & 3,0666 & 4,3098 & 3,2085 & 4,9448 & 3,2085 & 4,3036 & 4,4012 & 3,1932 & \\
\hline
\end{tabular}

7. Menghitung Nilai Entering dan Leaving Flow

$\varphi^{+}(i)=\frac{1}{m-1} \sum_{i^{\prime}=1}^{n} T P\left(i, i^{\prime}\right)\left(i \neq i^{\prime}\right)$ untuk Leaving Flow

$\varphi^{+}=\frac{1}{8-1} \times 7=1$

$\varphi^{+}=\frac{1}{8-1} \times 1,3625=0,1946$

$\varphi^{+}=\frac{1}{8-1} \times 6,5577=0,9368$

$\varphi^{+}=\frac{1}{8-1} \times 0=0$

$\varphi^{+}=\frac{1}{8-1} \times 6,5687=0,9384$ 


$$
\begin{aligned}
& \varphi^{+}=\frac{1}{8-1} \times 1,4609=0,2087 \\
& \varphi^{+}=\frac{1}{8-1} \times 1,0872=0,1553 \\
& \varphi^{+}=\frac{1}{8-1} \times 6,5993=0,9428 \\
& \varphi^{-}(i)=\frac{1}{m-1} \sum_{i^{\prime}=1}^{n} T P\left(i, i^{\prime}\right)\left(i \neq i^{\prime}\right) \text { untuk Entering } \\
& \varphi^{-}=\frac{1}{8-1} \times 3,0666=0,4381 \\
& \varphi^{-}=\frac{1}{8-1} \times 4,3098=0,6157 \\
& \varphi^{-}=\frac{1}{8-1} \times 3,2085=0,4584 \\
& \varphi^{-}=\frac{1}{8-1} \times 4,9448=0,7064 \\
& \varphi^{-}=\frac{1}{8-1} \times 3,2085=0,4584 \\
& \varphi^{-}=\frac{1}{8-1} \times 4,3036=0,6148 \\
& \varphi^{-}=\frac{1}{8-1} \times 4,4012=0,6287 \\
& \varphi^{-}=\frac{1}{8-1} \times 3,1932=0,4562
\end{aligned}
$$

8. Menghitung Net Flow

Menghitung dari perangkingan (i) untuk setiap alternatif lainnya.

$$
\begin{aligned}
& \varphi(i)=\varphi^{+}(i)-\varphi^{-}(i) \\
& =1-0,4381=0,5619 \\
& =0,1946-0,6157=-0,4210 \\
& =0,9368-0,4584=0,4785 \\
& =0-0,7064=-0,7064 \\
& =0,9384-0,4584=0,48 \\
& =0,2087-0,6148=-0,4061 \\
& =0,1553-0,6287=-0,4734 \\
& =0,9428-0,4562=0,4866
\end{aligned}
$$

9. Perangkingan alternatif

Dari tahapan perhitungan pada pemeringkatan ini diambil nilai net flow tertinggi untuk menentukan alternatif yang terpilih sebagai kepala jurusan berdasarkan metode extended promethee II dan dapat dilihat

Tabel 12. Hasil akhir

\begin{tabular}{lcccc}
\hline \multicolumn{1}{c}{ Alternatif } & Leaving Flow & Entering & Net Flow & Peringkat \\
\hline Djaniur Sinurat, S.Pd & 1,0000 & 0,4381 & 0,5619 & 1 \\
Iswanto, S.Pd & 0,9428 & 0,4562 & 0,4866 & 2 \\
Drs. Jatiman Simbolon, S.Pd & 0,9384 & 0,4584 & 0,4800 & 3 \\
Ekosusilo Sitanggang, S.Pd & 0,9368 & 0,4584 & 0,4785 & 4 \\
July Heriadi, S.Ag, M.Pd & 0,2087 & 0,6148 & $-0,4061$ & 5 \\
Rika Afriyanti, S.Pd, M.Pd & 0,1946 & 0,6157 & $-0,4210$ & 6 \\
Rachel Fransiska Sembiring, S.Pd & 0,1553 & 0,6287 & $-0,4734$ & 7 \\
Listivia Manao, S.Pd & 0,0000 & 0,7064 & $-0,7064$ & 8 \\
\hline
\end{tabular}

\section{KESIMPULAN}

Berdasarkan dari penelitian yang telah penulis lakukan pada bab-bab sebelumnya, maka didapatkan kesimpulan Prosedur penentuan kepala jurusan yang berlaku di SMK Negeri 1 Perbaungan sesuai dengan permasalahan yang diangkat oleh penulis. Metode Entropy dapat diterapkan untuk menentukan nilai bobot dari kriteria-kriteria yang digunakan dalam penentuan kepala jurusan. Dengan menggunakan metode EXPROM II dinilai dapat menyelesaikan permasalahan dalam penentuan kepala jurusan.

\section{REFERENCES}

[1] Efraim Turban and Jay E. Aronson, Decision Support System and Intelligent Systems. 2001.

[2] M. Mesran, R. Rusiana, and M. Sianturi, "Decision Support System for Termination of Employment using Elimination 
and Choice Translation Reality Method," J. Teknol. dan Sist. Komput., vol. 6, no. 4, p. 135, 2018.

[3] S. H. Sahir et al., "The Preference Selection Index Method in Determining the Location of Used Laptop Marketing," Int. J. Eng. Technol., vol. 7, pp. 260-263, 2018.

[4] D. Nofriansyah, Multi Criteria Decision Making (MCDM) Pada Sistem Pendukung Keputusan. Yogyakarta: CV.Budi Utama, 2017.

[5] D. Nofriansyah, Konsep Data Mining Vs Sistem Pendukung Keputusan. 2015.

[6] T. Limbong et al., Sistem Pendukung Keputusan: Metode \& Implementasi. Medan: Yayasan Kita Menulis, 2020.

[7] A. S. Harahap, Tulus, and E. Budhiarti, "PENERAPAN METODE ENTROPY DAN METODE PROMETHEE DALAM MERANGKING KUALITAS GETAH KARET,” Pelita Inform., vol. 16, no. 3, pp. 208-213, 2017.

[8] K. D. Maisari, D. Andreswari, and R. Efendi, "Implementasi Metode TOPSIS dengan Pembobotan Entropy untuk Penentuan Calon Penerima Bantuan Siswa Miskin (BSM) APBD Kota Bengkulu( Studi Kasus : SMAN 8 Kota Bengkulu ),"J. Rekursif, vol. 5, no. 2, pp. 179-194, 2017.

[9] S. R. Ningsih and A. P. Windarto, "Penerapan Metode Promethee II pada Dosen Penerima Hibah P2M Internal," InfoTekJar (Jurnal Nas. Inform. dan Teknol. Jaringan), vol. 3, no. 1, pp. 20-25, 2018.

[10] M. Mesran, S. D. Nasution, S. Syahputra, A. Karim, and E. Purba, "Implementation of the Extended Promethee II in Upgrade Level of Mechanic,” Int. J. Sci. Res. Sci. Technol., vol. 4, no. 2, pp. 125-130, 2018.

[11] M. Fadlina, L. T. Sianturi, A. Karim, "Best Student Selection Using Extended Promethee II Method," Int. J. Recent Trends Eng. Res, vol. 3 no.8, pp. 21-29, 2017. 